\title{
Pyruvate Aldol Condensation Product: A Metabolite that Escaped Synthetic Preparation for Over a Century
}

Andro C. Rios ${ }^{\star a, b, c}$ Partha P. Berad ${ }^{d},{ }^{2}$ Jennifer A. Moreno ${ }^{b},{ }^{c}$ and George Cooper ${ }^{a, c}$

aExobiology Branch, Space Science and Astrobiology Division, NASA Ames Research Center, Bldg N-239 Mail Stop 239-4, Moffett Field, CA 94035, USA

bBlue Marble Space Institute of Science

${ }^{c}$ Center for the Emergence of Life, NASA Ames Research Center

${ }^{\mathrm{d} A s t r o p h y s i c s}$ Branch, Space Science and Astrobiology Division, NASA Ames Research Center

eBay Area Environmental Research Institute

*Corresponding Author e-mail: andro.c.rios@nasa.gov 


\section{Table of Contents}

Title

Page

General Procedures

S3

LC-MS Methods

S3-S4

Table S1. Summary of Retention Times Determined by LC-MS

S5

Figure S1. Chromatograms of $\mathrm{HMOG}$ reaction in $0.1 \mathrm{M} \mathrm{HCl}$

S6

Figure S2. Chromatograms of $\mathrm{HMOG}$ reaction in $0.1 \mathrm{M} \mathrm{HCl}$ and oxidative decarboxylation

S7

Figure S3. Chromatograms of Zymonic acid reaction in $0.1 \mathrm{M} \mathrm{HCl}$

Figure S4. Chromatograms of Zymonic and HMOG reactions at $\mathrm{pH} 10$

Figure S5. Chromatograms of Z-OMPD and oxidative decarboxylation

Figure S6. Chromatograms to identify 4-MEOG

Figure S7. Chromatograms to identify E-OMPD

Figure S8. Time course reaction monitoring of HMOG, Zymonic, Z-OMPD

S14

Scheme S1. Isomerization among all five isomers of OMPD via keto-enol tautomerization

Figure S9. ${ }^{1} \mathrm{H}$ and ${ }^{13} \mathrm{C}$ NMR spectra of HMOG,2

Figure S10. ${ }^{1} \mathrm{H}$ and ${ }^{13} \mathrm{C}$ NMR spectra methylzymonate ester, 11

Figure S11. ${ }^{1} \mathrm{H}$ and ${ }^{13} \mathrm{C}$ NMR spectra of crystalline zymonic acid, 3

Figure S12. ${ }^{1} \mathrm{H}$ and ${ }^{13} \mathrm{C}$ NMR spectra of zymonic acid from hydrolysis of 11

Figure S13. ${ }^{1} \mathrm{H}$ and ${ }^{13} \mathrm{C}$ NMR spectra of 12

Figure S14. ${ }^{1} \mathrm{H}-{ }^{13} \mathrm{C}$ HSQC NMR spectra of 12

Figure S15. ${ }^{1} \mathrm{H}$ and ${ }^{13} \mathrm{C}$ NMR spectra of 12

Figure S16. ${ }^{1} \mathrm{H}$ and ${ }^{13} \mathrm{C}$ NMR spectra of 4

Figure S17. ${ }^{1} \mathrm{H}-{ }^{13} \mathrm{C}$ HSQC NMR spectra of 4

Figure S18. ${ }^{1} \mathrm{H}$ and ${ }^{13} \mathrm{C}$ NMR spectra of Pyruvic Acid commercial source

Figure S19. ${ }^{1} \mathrm{H}$ NMR spectra of crude product mixtures for synthesis of 12 


\section{General Procedures}

Reagents were purchased from Sigma-Aldrich, VWR, Acros, and were used without further purification. Solvents and NMR solvents were purchased from VWR. Synthesis reactions were monitored with analytical thin-layer chromatography (TLC) performed on pre-coated silica gel aluminum-backed plates (Merck Kieselgel 60 F254). Column chromatography was performed with silica gel particle size $40-63 \mu \mathrm{m}$. Chemicals obtained from syntheses were purified by flash column chromatography or described otherwise. Origin 2018 graphing program analysis software (OriginLab Corporation, North Hampton, MA, USA) was used to replot data from chromatograms, mass spectra and reaction monitoring graphs.

Safety: No unexpected or unusually high safety hazards were encountered during the course of this research

NMR Analysis: Spectra were obtained on a Bruker $500 \mathrm{MHz}$ NMR with an Avance III HD console located at the NMR Facility at the University of California Santa Cruz.

ESI-MS: Analyses for synthesized compounds were performed on a Thermo Finnigan LCQ Deca Max XP (Thermo-Fisher San Jose) equipped with an electrospray ionization source probe assembly with detection in the negative mode polarity using the sample loop injections with introduction using a 90:10 eluent mixture of B:A described below. Samples were diluted in Eluent $\mathrm{C}$ and filtered before introduction into the spectrometer.

\section{LC-MS Methods}

Eluent Preparation: Eluent A consisted of an aqueous $20 \mathrm{mM}$ ammonium formate solution with added formic acid at $\mathrm{pH} 3$. Eluent $\mathrm{B}$, consisted of a $90: 10$ Acetonitrile: $\mathrm{H}_{2} \mathrm{O}(\mathrm{v} / \mathrm{v} \%)$ mixture with aqueous $20 \mathrm{mM}$ ammonium formate with added formic acid at $\mathrm{pH} 3$. Eluent C, consisted of a $80: 20$ Acetonitrile: $\mathrm{H}_{2} \mathrm{O}(\mathrm{v} / \mathrm{v} \%)$ mixture with aqueous $20 \mathrm{mM}$ ammonium formate with added formic acid at $\mathrm{pH} 3$. Eluent $\mathbf{A}$ and Eluent $\mathbf{B}$ were prepared in 500 $\mathrm{mL}$ batches. A stock solution consisting of $200 \mathrm{mM}$ ammonium formate with added formic acid to lower the $\mathrm{pH}$ to 3 was first prepared in a $500 \mathrm{~mL}$ volumetric flask. Preparation of Eluent A was made in a $500 \mathrm{~mL}$ volumetric flask by adding $50 \mathrm{~mL}$ of the $200 \mathrm{mM}$ ammonium formate stock at $\mathrm{pH} 3$ then diluting with deionized $\mathrm{H}_{2} \mathrm{O}$. Preparation of Eluent B was made in a $500 \mathrm{~mL}$ volumetric flask by adding $50 \mathrm{~mL}$ of the $200 \mathrm{mM}$ ammonium formate stock, $\mathrm{pH} 3$, and diluting gradually with LC-MS grade acetonitrile and with mixing and letting the solution warm to room temperature before filling to mark. Eluent $\mathbf{C}$ was prepared in a $250 \mathrm{~mL}$ volumetric flask by adding $25 \mathrm{~mL}$ of the $200 \mathrm{mM}$ ammonium formate stock, $\mathrm{pH} 3$, and $25 \mathrm{~mL}$ of D.I. water, mixed then diluted with acetonitrile and thoroughly mixed and stored.

Sample preparation: In all cases, unless otherwise specified, LC-MS sample preparation consisted of $25 \%$ aqueous solution and $75 \%$ Eluent C. Typically $50-100 \mu \mathrm{L}$ of the reaction mixture was removed and was diluted to a total volume of $250 \mu \mathrm{L}$ with deionized water, to which $750 \mu \mathrm{L}$ of Eluent $\mathbf{C}$ was added and mixed and the mixture was filtered 
through a $0.2 \mu \mathrm{m}$ nylon membrane syringe filter into a $2 \mathrm{~mL}$ sized auto sampler LC-MS vial and fitted with a screw cap.

LC-MS Analysis: Analyses of reaction mixtures were performed using a Thermo Finnigan LCQ Deca Max XP equipped with an electrospray ionization source using a SeQuant ${ }^{\circledR}$

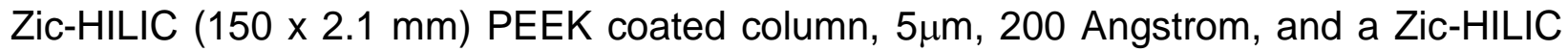
guard column ( $20 \times 2.1 \mathrm{~mm}$ ). Nebulizer gas (nitrogen) flow rate was set to 31 arbitrary (arb) units, Aux sweep gas (nitrogen) was set to 10 arb units. Spray voltage was $3.5 \mathrm{kV}$, capillary voltage, $-36 \mathrm{~V}$, capillary temperature at $325^{\circ} \mathrm{C}$ and column oven temperature set at $30^{\circ} \mathrm{C}$. The volume of samples injected were typically $3 \mu \mathrm{L}$ and the elution profile consisted of an isocratic mixture of $90 \%$ Eluent B, and $10 \%$ Eluent $\mathbf{A}$ at $0.2 \mathrm{~mL} / \mathrm{min}$, and monitored over 23 mins. 
Table S1. Summary of Retention Times Determined by LC-MS

\begin{tabular}{|c|c|c|c|}
\hline Compound & Structure & $\begin{array}{l}\text { Retention time } \\
\text { (min) }\end{array}$ & $\begin{array}{c}\text { Molecular ion, } \\
\mathbf{m} / \mathbf{z}(-)\end{array}$ \\
\hline $\begin{array}{c}13 \\
\text { Citraconic }\end{array}$ & & 2.80 & 129 \\
\hline $\begin{array}{l}\mathbf{9} \\
\text { Methylsuccinic } \\
\text { acid }\end{array}$ & & 3.25 & 131 \\
\hline $\begin{array}{c}15 \\
\text { Itaconic }\end{array}$ & & 3.65 & 129 \\
\hline $\begin{array}{c}4 \\
\text { (Z)-OMPD }\end{array}$ & & 4.00 & 157 \\
\hline $\begin{array}{c}1 \\
\text { Pyruvic }\end{array}$ & & 4.77 & 87 \\
\hline $\begin{array}{c}7 / 8 \\
\text { CHPD (E/Z) }\end{array}$ & & $\begin{array}{c}{ }^{*} 4.84 \\
\text { (tentative) }\end{array}$ & 157 \\
\hline $\begin{array}{c}3 \\
\begin{array}{c}\text { Zymonic } \\
\text { acid }\end{array}\end{array}$ & & 5.51 & 157 \\
\hline $\begin{array}{c}14 \\
\text { Mesaconic }\end{array}$ & & 7.46 & 129 \\
\hline $\begin{array}{c}\mathbf{6} \\
\text { 4-MEOG }\end{array}$ & & 8.35 & 157 \\
\hline $\begin{array}{c}2 \\
\text { HMOG } \\
\text { (Parapyruvic) }\end{array}$ & & 15.05 & 175 \\
\hline $\begin{array}{c}\mathbf{5} \\
(E)-\mathrm{OMPD}\end{array}$ & & 19.12 & 157 \\
\hline
\end{tabular}


A

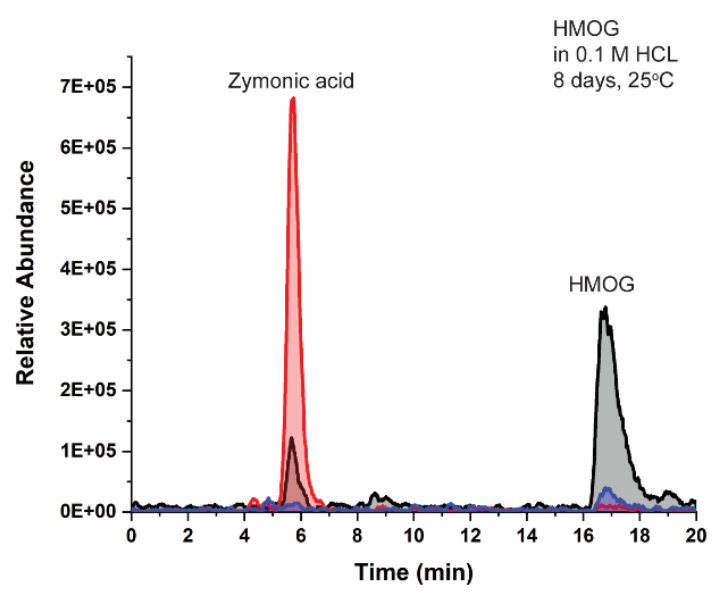

B

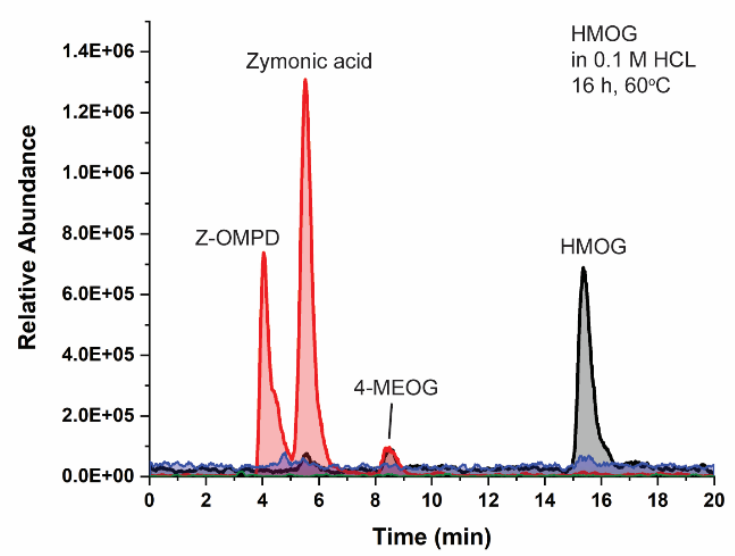

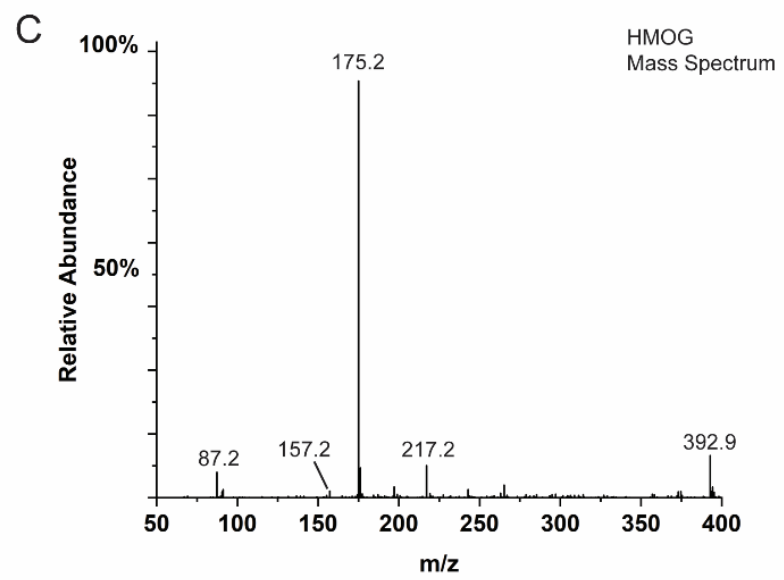

$\mathrm{D}$

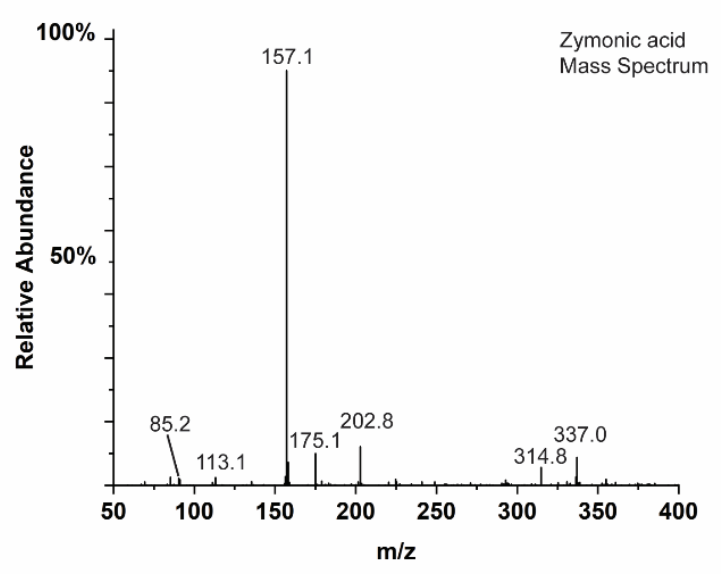

Figure S1. Extracted ion chromatograms of $\mathrm{HMOG}$, 2, reactions in $0.1 \mathrm{M}$ hydrochloric acid. A. Formation of zymonic acid, 3. B. Heating leads to the production of Z-OMPD, 4, and 4-MeOG, 6, after 16 hours at $60^{\circ} \mathrm{C}$. C. Mass spectrum of $\mathrm{HMOG}$ peak from panel $\mathrm{A}$, the masses higher than 175 represent added electrospray adducts of $(\mathrm{M}-\mathrm{H})$ or $(2 \mathrm{M}-\mathrm{H})$. D. Mass spectrum of Zymonic acid, the masses higher than 157, represent added electrospray ionization adducts of $(\mathrm{M}-\mathrm{H})$ or $(2 \mathrm{M}-\mathrm{H})$. Extracted ion peaks in negative mode: $\mathrm{red}(\mathrm{m} / \mathrm{z}=157)$, green $(\mathrm{m} / \mathrm{z}=131)$, purple $(\mathrm{m} / \mathrm{z}=$ $129)$, black $(\mathrm{m} / \mathrm{z}=175)$, blue $(\mathrm{m} / \mathrm{z}=87)$.

Experimental for Figure S1. In a $10 \mathrm{~mL}$ volumetric flask was added $55 \mathrm{mg}$ of HMOG disodium salt, 2, and dissolved in $0.1 \mathrm{M} \mathrm{HCl}$ and filled to the mark. After immediate thorough mixing, the solution was split into two reaction vials, one of which was set in a $60^{\circ} \mathrm{C}$ heating block and the other left at room temperature. Sampling occurred after 16 hours at $60^{\circ} \mathrm{C}$, while the room temperature reaction was sampled after eight days. Sampling for both consisted of removing 150 $\mu \mathrm{L}$ of the reaction mixture and were processed for LC-MS analysis as previously described. 

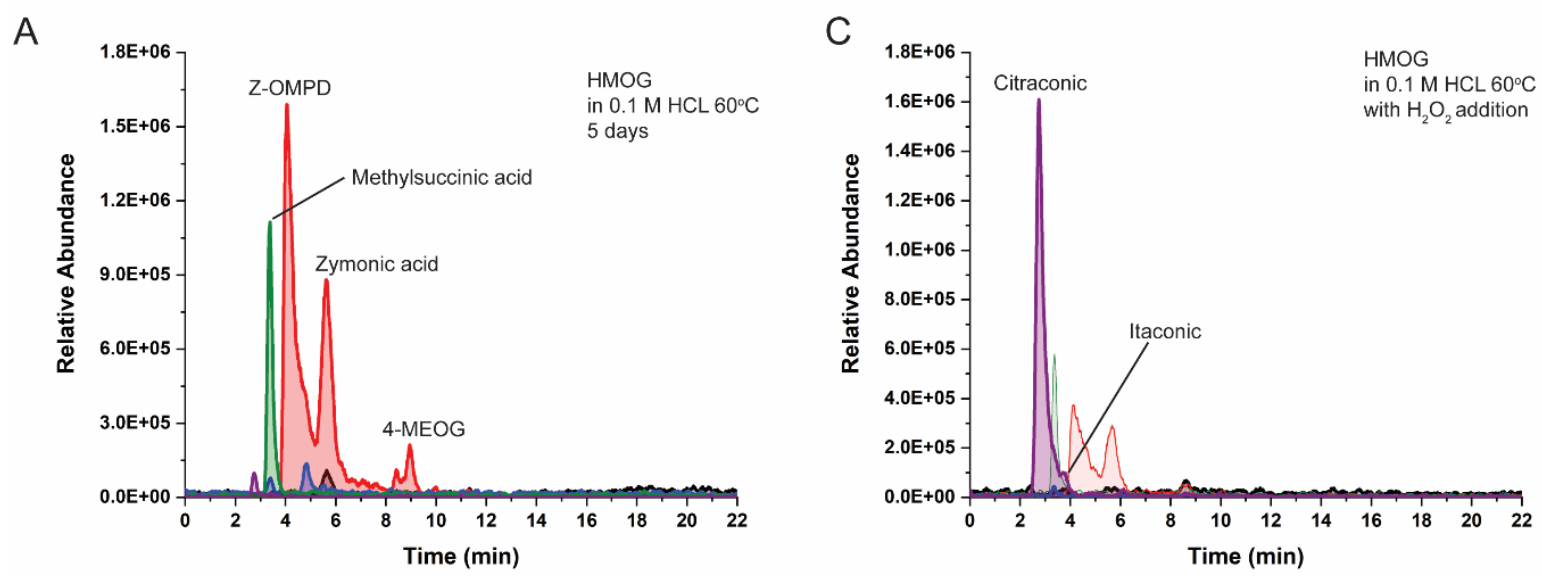

B
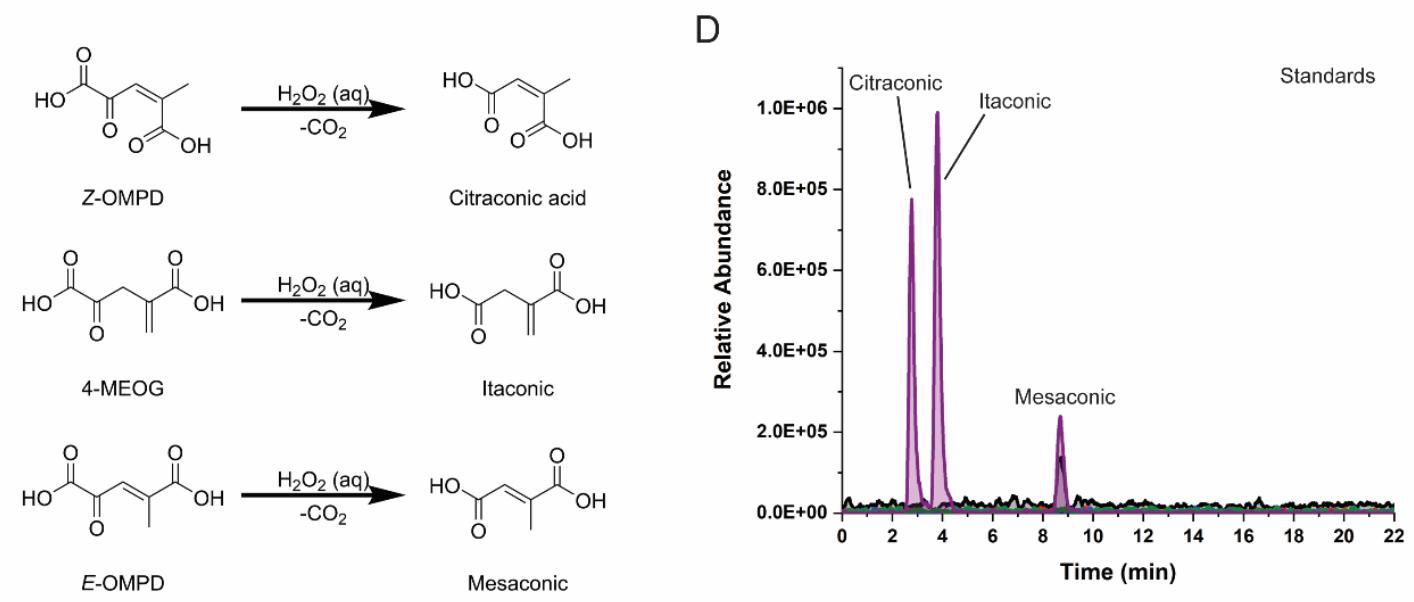

Figure S2. Extracted ion chromatogram of an $\mathrm{HMOG}, 2$, reaction in $0.1 \mathrm{M}$ hydrochloric acid. A. Sustained heating of HMOG leads to two isomers of OMPD (4 and $\mathbf{6})$ and methylsuccinic acid, $\mathbf{9}$. B. Isomeric identity of keto acids can be gained from a simple oxidative decarboxylation reaction leading to stable, unsaturated C5 dicarboxylic acids $(\mathbf{1 3}, \mathbf{1 4 , 1 5})$ These reactions are well known to quantitatively decarboxylate keto acids by hydrogen peroxide ${ }^{1}$ especially at $\mathrm{pH}>7 \mathbf{C}$. Incomplete oxidation of a sample from the acidic reaction mixture in panel A produces a prominent citraconic acid,13, peak and a smaller peak of itaconic acid, 15. D. All three of the C5 unsaturated diacids can be chromatographically resolved. Extracted ion peaks in negative mode: red $(\mathrm{m} / \mathrm{z}=$ $157)$, green $(\mathrm{m} / \mathrm{z}=131)$, purple $(\mathrm{m} / \mathrm{z}=129)$, black $(\mathrm{m} / \mathrm{z}=175)$, blue $(\mathrm{m} / \mathrm{z}=87)$.

Experimental for Figure S2. Panel A. The reaction mixture used was prepared in the same fashion detailed in Figure $\mathrm{S} 1$ and sampled after 5 days at $60^{\circ} \mathrm{C}$. Panel C: Oxidation of the reaction mixture was performed by removing $150 \mu \mathrm{L}$ and mixing with $50 \mu \mathrm{L}$ of deionized water and $50 \mu \mathrm{L}$ of aqueous hydrogen peroxide (30\%). The mixture was allowed to react for 30 mins before final procedures for sample preparation were followed. Panel D: $10 \mathrm{mM}$ solutions of commercially available citraconic,13, mesaconic, 14, and itaconic, 15, acid were prepared in water separately before a diluted mixture was prepared in $1 \mathrm{~mL}$ of water with itaconic (1:10 dilution), citraconic (1:20 dilution), and mesaconic (1:5 dilution) acid. From this combined dilution, $250 \mu \mathrm{L}$ was removed and the remaining procedures were followed as previously described under LC-MS analysis. 

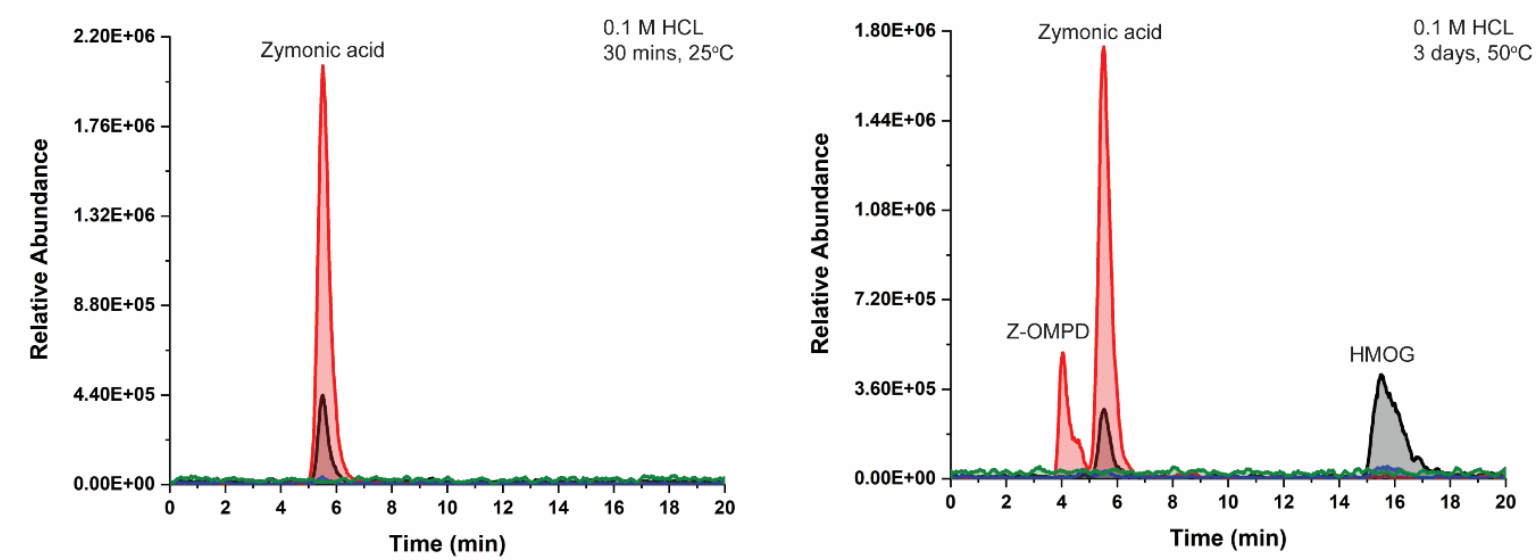

B
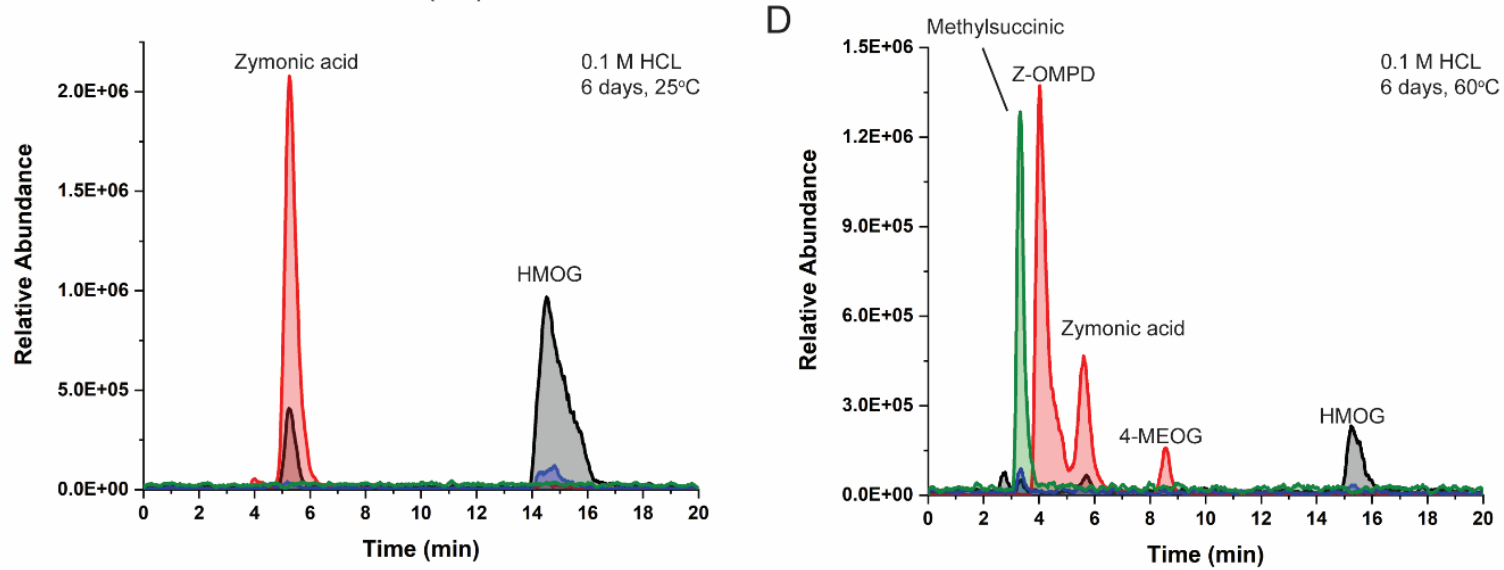

Figure S3. Extracted ion chromatograms of zymonic acid, 3, reactions in $0.1 \mathrm{M}$ hydrochloric acid. A. Pure zymonic acid starting material at room temperature. B Analysis after six days at room temperature shows significant production of HMOG, 2. C. Upon heating, production of Z-OMPD, 4, is observed along with HMOG, 2. D. Raising temperature to $60^{\circ} \mathrm{C}$ leads to greater production of Z-OMPD, but also formation of methylsuccinic acid,9, and 4-MEOG, 6, which begins to resemble the chromatogram of Figure S2A. Extracted ion peaks in negative mode: $\mathrm{red}(\mathrm{m} / \mathrm{z}=$ $157)$, green $(m / z=131)$, purple $(m / z=129)$, black $(m / z=175)$, blue $(m / z=87)$.

Experimental for Figure S3. In a $5 \mathrm{~mL}$ volumetric flask was added $27 \mathrm{mg}$ of zymonic acid, 3, and dissolved in $0.1 \mathrm{M}$ hydrochloric acid. After thorough mixing the solution was split into two reaction vials, one of which was set in a pre-heated $50^{\circ} \mathrm{C}$ heating block and the other left at room temperature. Room temperature reactions were sampled after 30 mins and 6 days. Heated reactions were sampled after 3 days at $50^{\circ} \mathrm{C}$, then heating was increased to $60^{\circ} \mathrm{C}$ and sampled 3 days later. Sampling for all consisted of taking a $150 \mu \mathrm{L}$ aliquot of the reaction mixture: and the remaining procedures were followed as previously described under LC-MS analysis. 

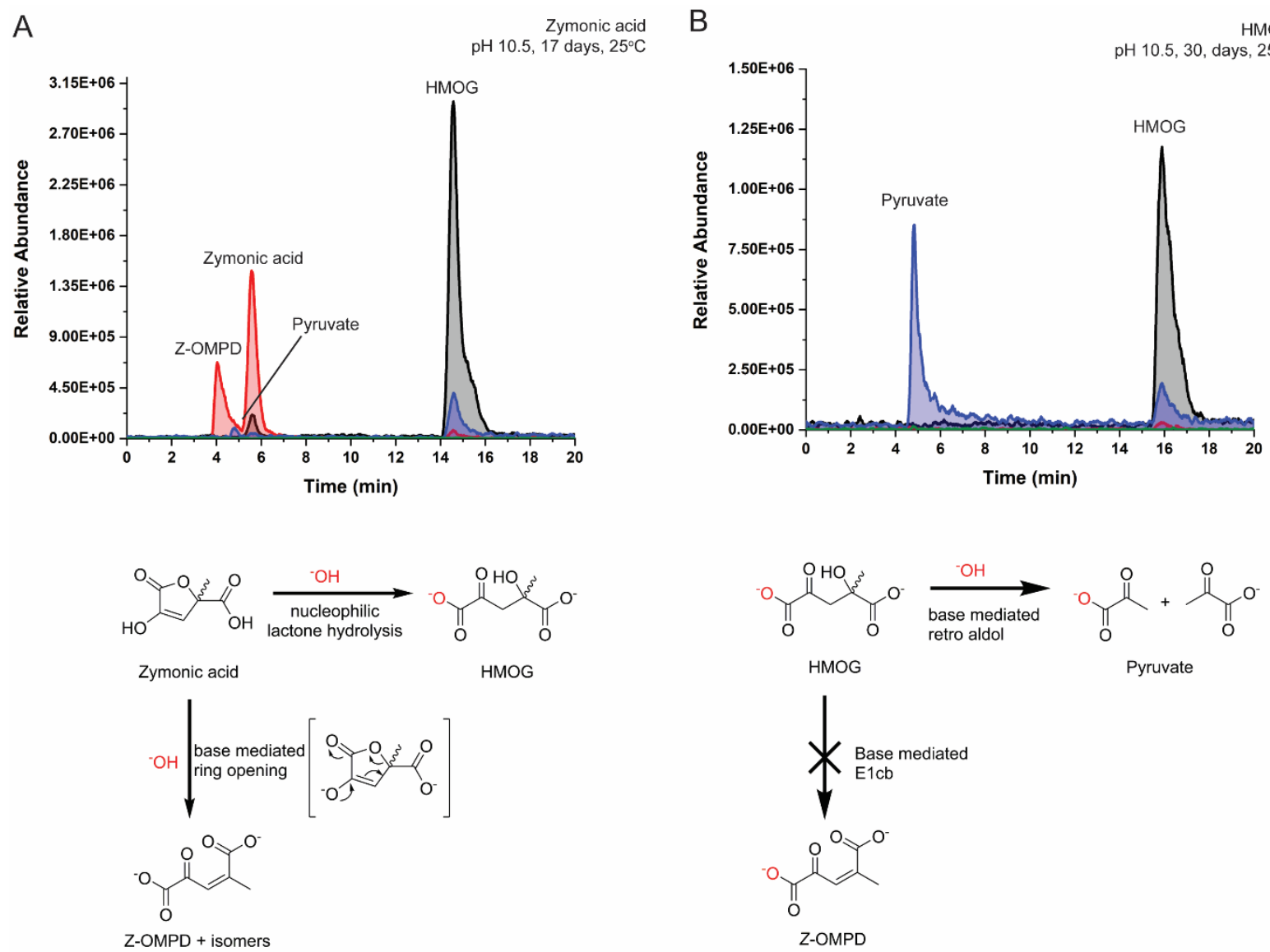

Figure S4. A. Extracted ion chromatograms of zymonic acid, 3, under alkaline $\mathrm{pH}$ for extended periods at room temperature leads to two dominant products, HMOG, 2, and Z-OMPD, 4 . This is suggestive that two pathways are possible as shown in the scheme below the chromatogram. B. Subjecting HMOG to the same alkaline $\mathrm{pH}$ for extended periods at room temperature promotes a retro-aldol reaction leading to exclusive pyruvate formation with little to no evidence of Z-OMPD. This further supports the assumption that zymonic acid leads to Z-OMPD. Extracted ion peaks in negative mode: red $(\mathrm{m} / \mathrm{z}=157)$, green $(\mathrm{m} / \mathrm{z}=131)$, purple $(\mathrm{m} / \mathrm{z}=129)$, black $(\mathrm{m} / \mathrm{z}=175)$, blue $(\mathrm{m} / \mathrm{z}=87)$.

Experimental for Figure S4. Panel A: In a $5 \mathrm{~mL}$ volumetric flask was added $34 \mathrm{mg}$ of zymonic acid,3, and in $0.1 \mathrm{M}$ sodium carbonate buffer ( $\mathrm{pH} 10.5$ ) and re-adjusted to $\mathrm{pH} 10.5$ with the dropwise addition of $1 \mathrm{M}$ sodium hydroxide before filling to mark. After thorough mixing the solution was left at room temperature. Room temperature reactions were sampled after 17 days by removing $150 \mu \mathrm{L}$ of the reaction mixture and processed for LC-MS analysis as previously described. Panel B: In a $10 \mathrm{~mL}$ volumetric flask was added $62 \mathrm{mg}$ of HMOG, 2, disodium salt and dissolved in $0.1 \mathrm{M}$ carbonate buffer ( $\mathrm{pH}$ 10.5), no $\mathrm{pH}$ adjustment was needed. After immediate thorough mixing, the solution was left at room temperature. Sampling occurred periodically but a final sample after 30 days was conducted by removing $150 \mu \mathrm{L}$ of the reaction mixture and processed for LC-MS analysis as previously described. 
A

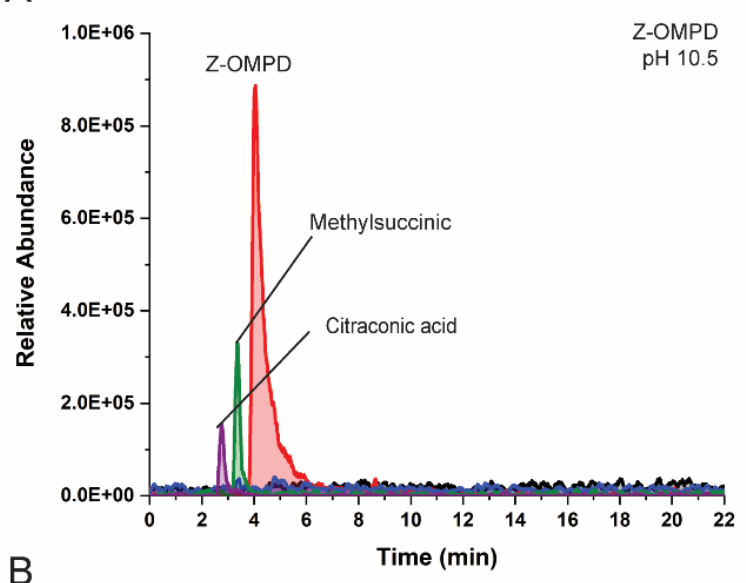

B

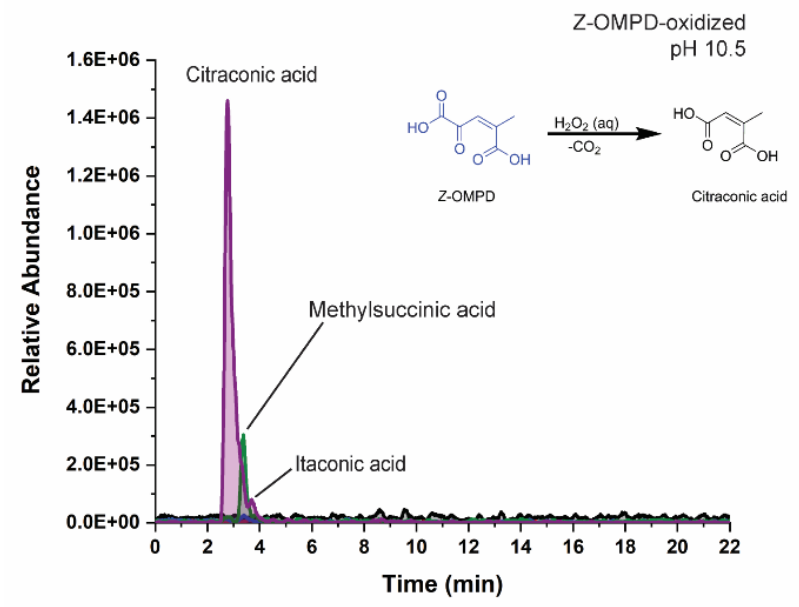

C

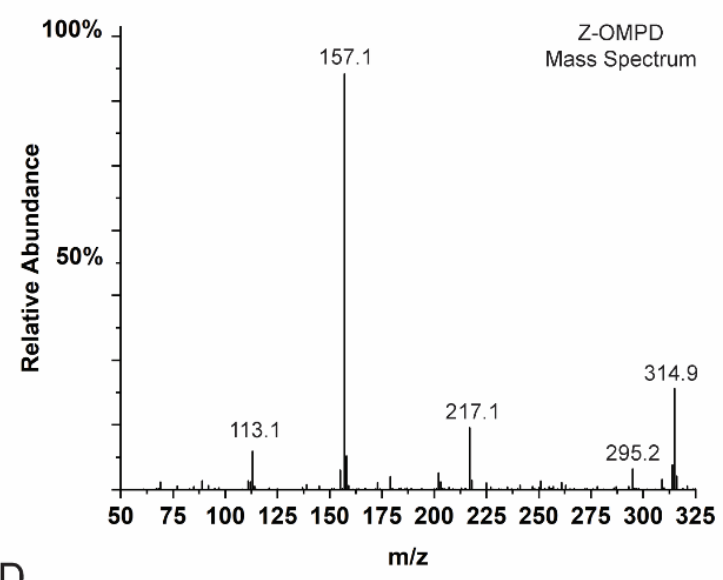

D

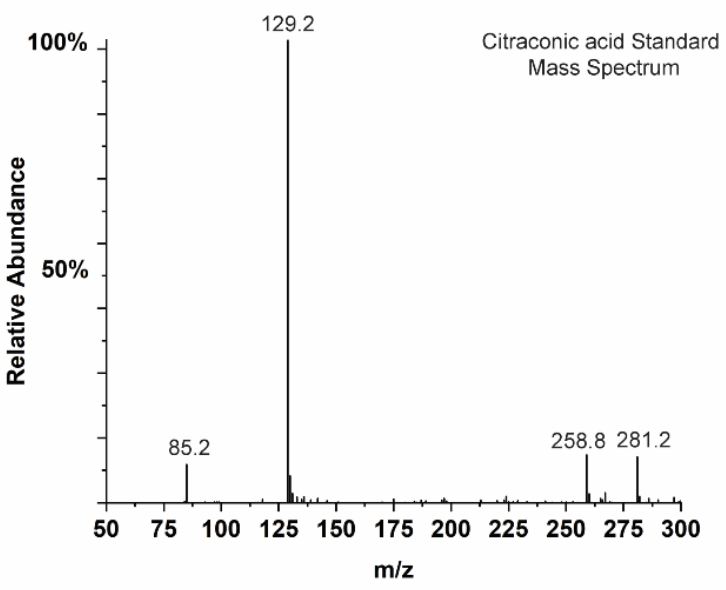

Figure S5. Extracted ion chromatograms and mass spectra. A. Synthetically produced ZOMPD,4, under alkaline conditions with degradative decarboxylation impurities. B. Oxidative decarboxylation of Z-OMPD leads to nearly complete conversion to citraconic acid, 13. Besides residual methylsuccinic acid, 9, a small shoulder of itaconic acid, 15, is observable, perhaps due to small amounts of prior keto acid isomerization. C. Mass spectrum of synthetically produced ZOMPD, the masses higher than 157 represent added electrospray ionization adducts with $(\mathrm{M}-\mathrm{H})$ or (2M-H). D. Citraconic acid, 13, arising from Z-OMPD oxidation matches with a citraconic acid standard mass spectrum shown here. The masses higher than 129, represent electrospray ionization adducts with $(\mathrm{M}-\mathrm{H})$ or $(2 \mathrm{M}-\mathrm{H})$. Extracted ion peaks in negative mode: $\mathrm{red}(\mathrm{m} / \mathrm{z}=157)$, green $(\mathrm{m} / \mathrm{z}=131)$, purple $(\mathrm{m} / \mathrm{z}=129)$, black $(\mathrm{m} / \mathrm{z}=175)$, blue $(\mathrm{m} / \mathrm{z}=87)$.

Experimental for Figure S5. Panel A: In a $5 \mathrm{~mL}$ volumetric flask was added $12 \mathrm{mg}$ of synthetically prepared Z-OMPD, 4, oil dissolved in $0.1 \mathrm{M}$ carbonate buffer ( $\mathrm{pH} 10.5)$ and re-adjusted to $\mathrm{pH} 10.5$ with the dropwise addition of $1 \mathrm{M}$ sodium hydroxide before filling to mark. After thorough mixing a sample of $150 \mu \mathrm{L}$ was removed and processed for LC-MS analysis as previously described. Panel B: Oxidation consisted of removing $150 \mu \mathrm{L}$ of Z-OMPD solution and adding to $50 \mu \mathrm{L}$ of deionized water and $50 \mu \mathrm{L}$ of aqueous hydrogen peroxide (30\%). The mixture reacted for 30 mins before adding $750 \mu \mathrm{L}$ of Eluent $\mathrm{C}$ and filtering into an auto-sampler vial for immediate analysis. 

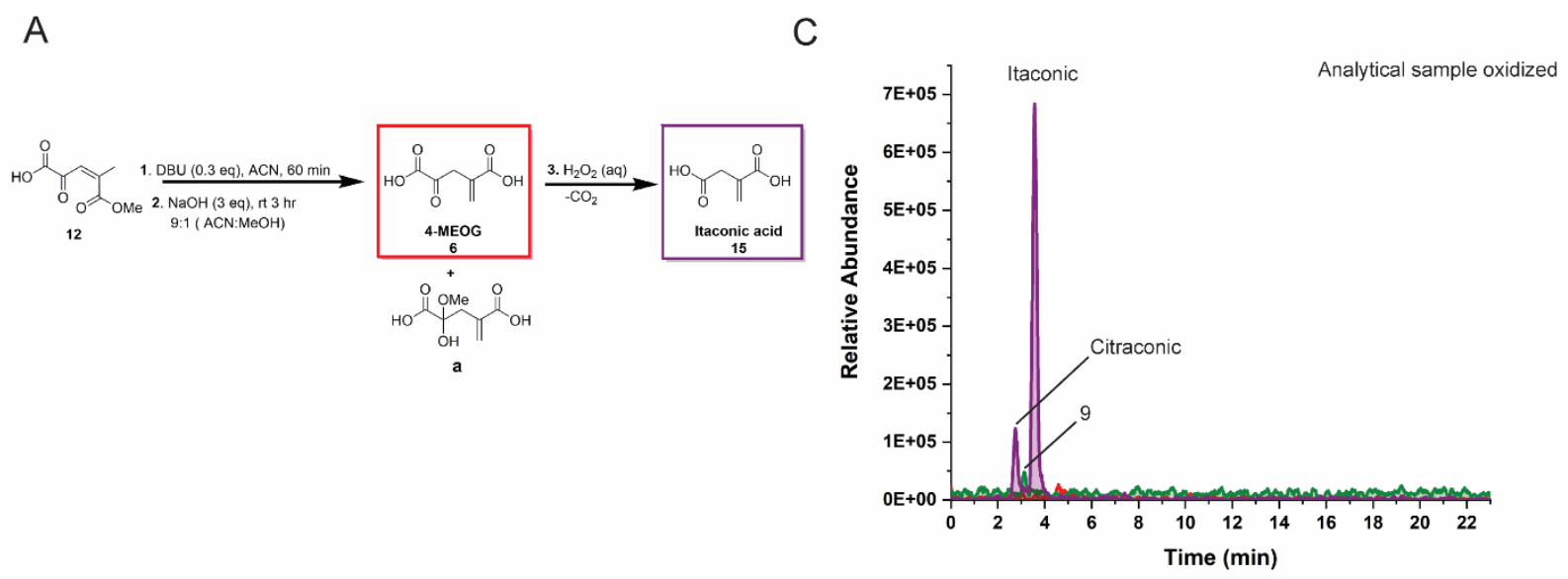

B
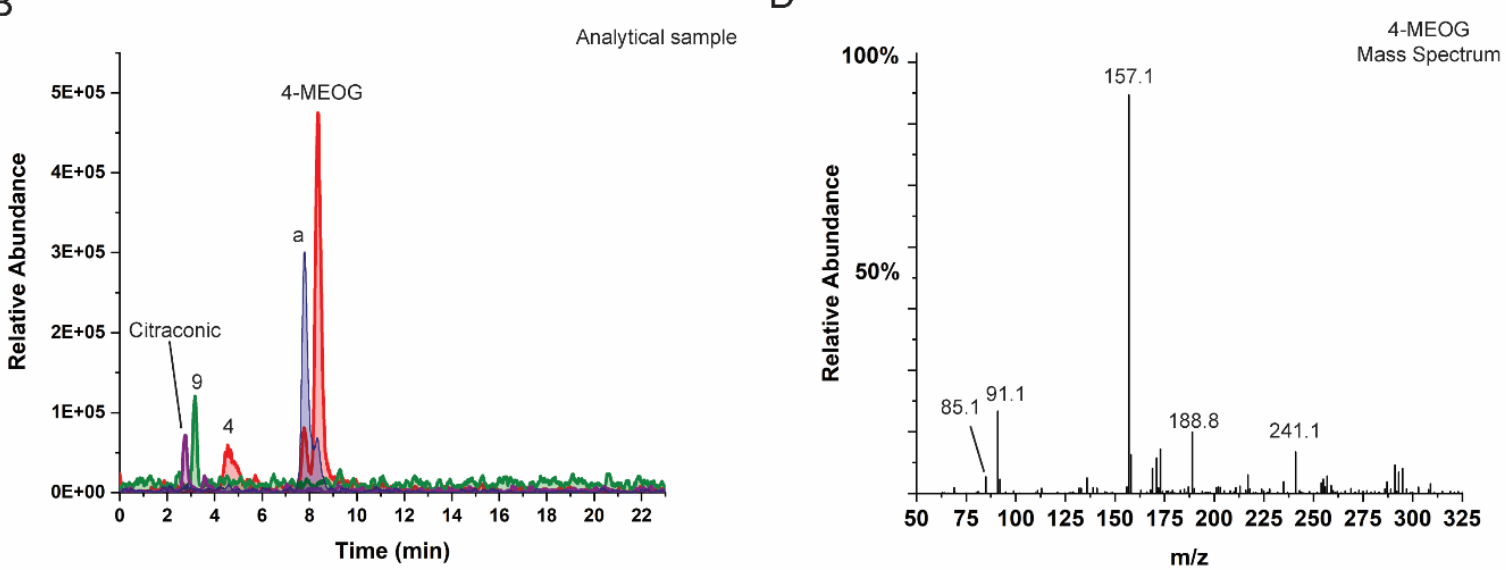

Figure S6. A. Hydrolytic scheme to generate an enrichment of 4-MEOG,6, from monoester-acid, 12, and subsequent oxidation to itaconic acid,15. B. Extracted ion chromatogram of crude hydrolysis reaction before oxidative decarboxylation showing the enrichment of the suspected 4MEOG, 6, isomer with other peaks observed including: a suspected methoxy hemi-ketal byproduct ,a, Z-OMPD, 4, methylsuccinic acid, 9, and citraconic acid, 13. C. Oxidation of the crude hydrolysis reaction leads to the expected enrichment of the itaconic acid, 15, which helps verify the 4-MEOG peak assignment from B. D. Mass spectrum of 4-MEOG, the masses higher than 157 represent added electrospray ionization adducts with $(\mathrm{M}-\mathrm{H})$ or $(2 \mathrm{M}-\mathrm{H})$ and the 189 is coelution from peak a in panel $\mathrm{B}$. The mass 91 is a formic acid dimer $(2 \mathrm{M}-\mathrm{H})$ originating from the eluent composition, and the 85 value is the only significant related daughter ion from 4-MEOG. Extracted ion peaks in negative mode: $\mathrm{red}(\mathrm{m} / \mathrm{z}=157)$, green $(\mathrm{m} / \mathrm{z}=131)$, purple $(\mathrm{m} / \mathrm{z}=129)$, black $(\mathrm{m} / \mathrm{z}=175)$, blue $(\mathrm{m} / \mathrm{z}=189)$.

Experimental for Figure S6. Panel A - C. In a $50 \mathrm{~mL}$ round bottom flask containing $15 \mathrm{~mL}$ of acetonitrile was added $26 \mathrm{mg}$ of compound 12, and to it was added $6 \mu \mathrm{L}$ of DBU $(1,8$ Diazabicyclo[5.4.0]undec-7-ene) and allowed to stir at room temperature. After $60 \mathrm{mins}, 18 \mathrm{mg}$ of crushed sodium hydroxide was added along with $1.6 \mathrm{~mL}$ of methanol and the reaction was briefly sonicated before allowing to stir at room temperature for another $3 \mathrm{hr}$. Solvent was removed by rotary evaporation and to the solid was added $10 \mathrm{~mL}$ of ethyl acetate and $3 \mathrm{~mL}$ of water that was acidified to $\mathrm{pH} 0$ with $3 \mathrm{M} \mathrm{HCL}$ and extracted once with ethyl acetate. The organic layer was dried over sodium sulfate. Two aliquots about $0.5 \mathrm{~mL}$ each were removed into analytical vials and the 
solvent was evaporated. To one vial, was added $250 \mu \mathrm{L}$ of deionized water, and $750 \mu \mathrm{L}$ of Eluent C. To the second vial was added $200 \mu \mathrm{L}$ of deionized water and $50 \mu \mathrm{L}$ of aqueous hydrogen peroxide (30\%) and the mixture was allowed to react for 30 mins before adding $750 \mu \mathrm{L}$ of Eluent $\mathrm{C}$, and both were filtered into separate auto-sampler vials for immediate analysis. Panel D: 10 $\mathrm{mM}$ solutions of commercially available citraconic, 13, mesaconic, 14, and itaconic, 15, acid were prepared in water separately before a diluted mixture was prepared in $1 \mathrm{~mL}$ of water with itaconic (1:10 dilution), citraconic (1:20 dilution), and mesaconic (1:5 dilution) acid. From this combined dilution, $250 \mu \mathrm{L}$ was removed and processed for LC-MS analysis as previously described.

A

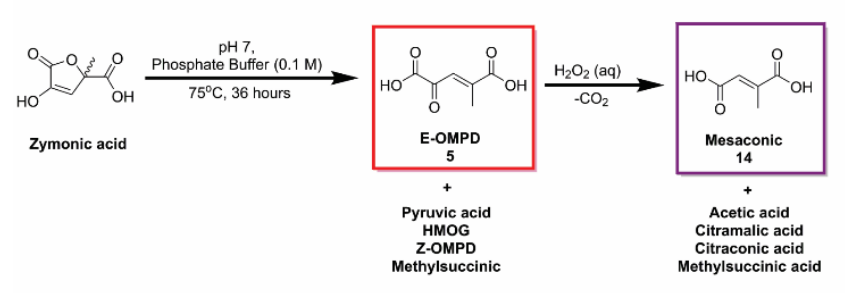

B

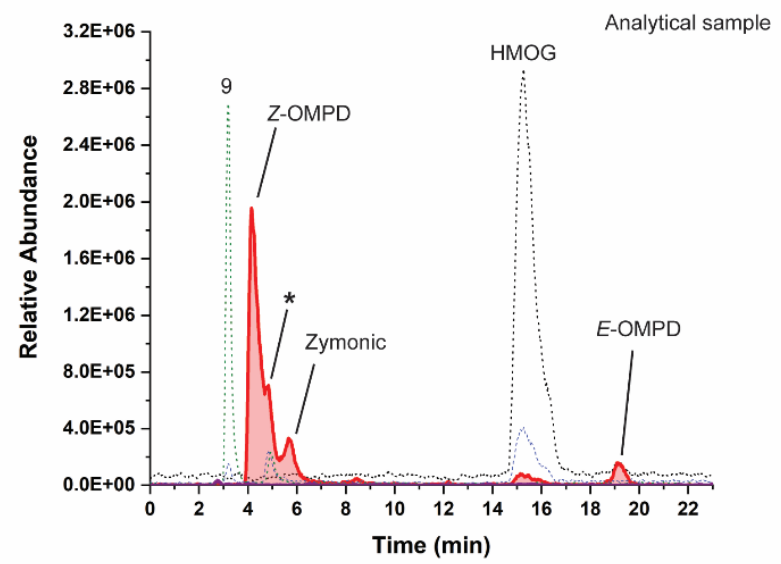

C

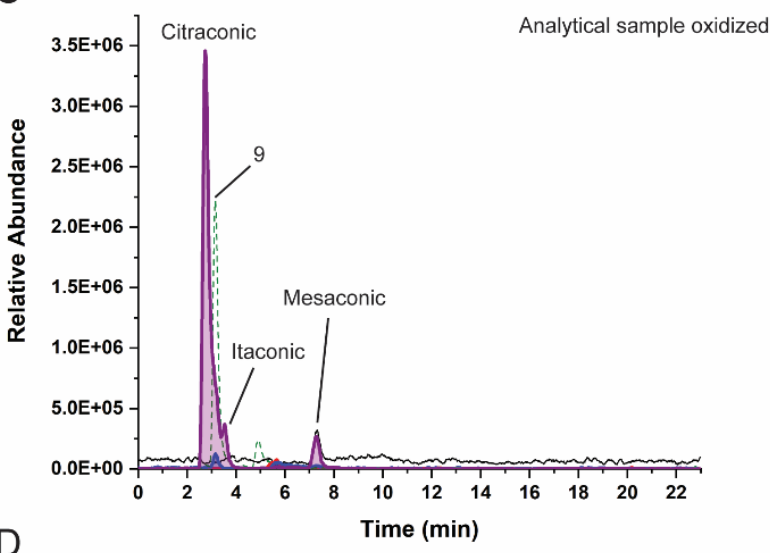

D

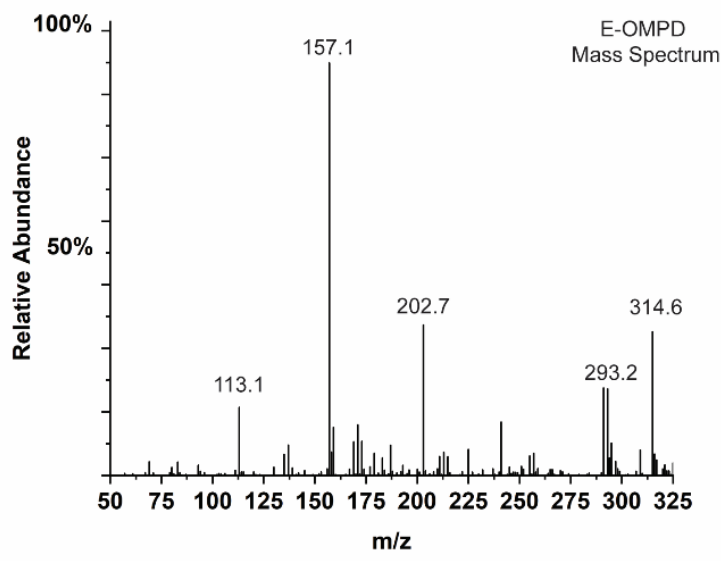

Figure S7. A. Reaction scheme to generate production of the E-OMPD isomer,5, among other products and subsequent oxidation to expected degradation products including mesaconic acid,14. B. Extracted ion chromatogram of crude reaction before oxidation showing evidence of suspected E-OMPD isomer along with the dominant isomer, Z-OMPD, 4, methylsuccinic, 9, HMOG, 2, zymonic acid, 3, and tentative assignment (*) of CHPD (7/8). C. Oxidation of the crude reaction leads to the expected formation of both citraconic, 13, and mesaconic acid, 14, which helps establish the E-OMPD, 5, peak assignment. The production of mesaconic acid only occurs when reaction mixtures containing the suspected E-OMPD peak at 19.19 mins are oxidized. The itaconic acid, 15, peak being formed could be a result of an isomerization from E-OMPD or the suspected CHPD, 7/8, during the oxidation reaction. D. Mass spectrum of E-OMPD, 5, the 
masses higher than 157 represent added electrospray ionization adducts with $(\mathrm{M}-\mathrm{H})$ or $(2 \mathrm{M}-\mathrm{H})$. The mass spectrum appears noisier given the lower signal of the peak shown in B. Extracted ion peaks in negative mode: red $(\mathrm{m} / \mathrm{z}=157)$, dotted green $(\mathrm{m} / \mathrm{z}=131)$, purple $(\mathrm{m} / \mathrm{z}=129)$, dotted black $(\mathrm{m} / \mathrm{z}=175)$, dotted blue $(\mathrm{m} / \mathrm{z}=87)$.

Experimental for Figure S7: In a $5 \mathrm{~mL}$ volumetric flask was added a solution containing $37 \mathrm{mg}$ of zymonic acid, 3, in a $0.1 \mathrm{M}$ sodium phosphate buffer ( $\mathrm{pH} 7)$ : the mixture was re-adjusted to $\mathrm{pH} 7$ with the dropwise addition of $1 \mathrm{M}$ sodium hydroxide before filling to the mark. The solution was transferred to a reaction vial and placed in a pre-warmed $75^{\circ} \mathrm{C}$ heating block and allowed to react, with periodic sampling every 24 hours until a sufficient peak abundance of the suspected E-OMPD isomer was observed. Sampling consisted of removing $250 \mu \mathrm{L}$ of the reaction mixture and was processed for LC-MS analysis as previously described. Chromatogram shown in B was taken after 36 hours of reaction time. At this point a second $250 \mu \mathrm{L}$ sample was removed from the reaction and to it was added $50 \mu \mathrm{L}$ of aqueous hydrogen peroxide (30\%) and the mixture was allowed to react for 1 hour before adding $700 \mu \mathrm{L}$ of Eluent $\mathrm{C}$ and filtering into a vial for immediate analysis by LC-MS. 

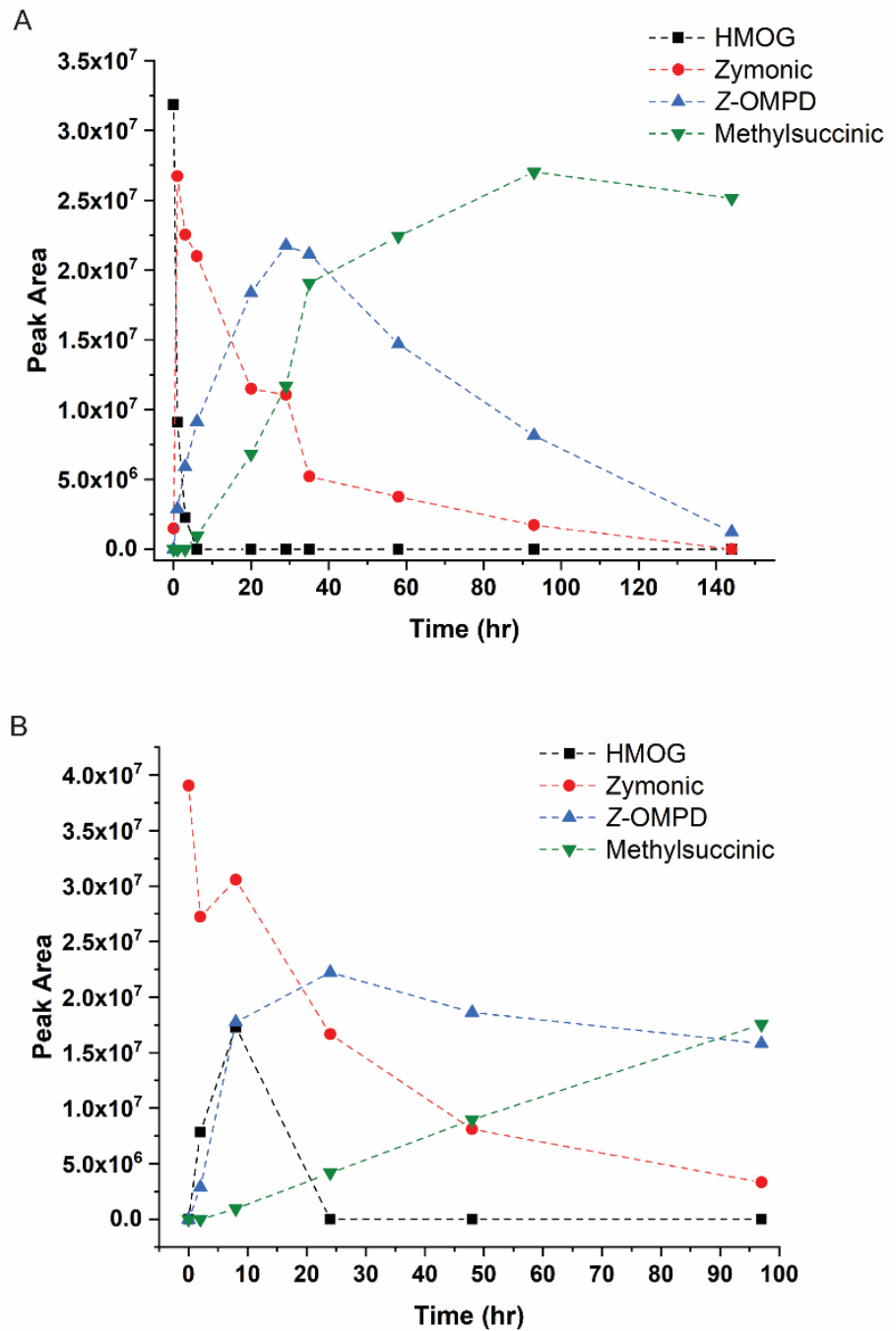

C

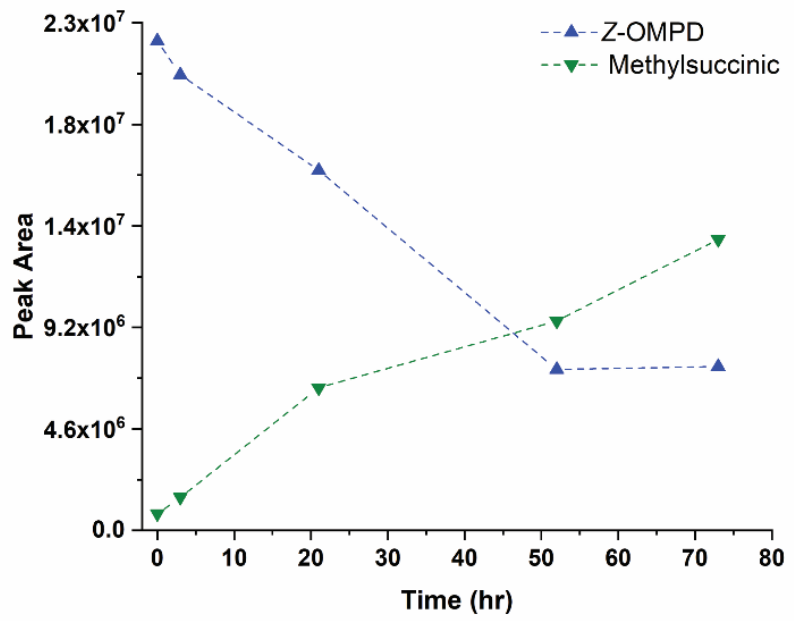

Figure S8. Time course reaction monitoring of starting material in $0.1 \mathrm{M}$ hydrochloric acid and $75^{\circ} \mathrm{C}$ A. HMOG, 2. B. Zymonic acid, 3. C. Z-OMPD,4. 
Experimental for Figure S8: Panel A. The same figure and conditions employed as Figure 2A, included here for comparison. Panel B. In a $5 \mathrm{~mL}$ volumetric flask was dissolved $10 \mathrm{mg}$ of zymonic acid, 3, in $0.1 \mathrm{M}$ hydrochloric acid and filled to the mark. After immediate thorough mixing the solution was transferred to a reaction vial with a cap and placed in a pre-heated $75^{\circ} \mathrm{C}$ heating block and allowed to react. At designated time points $100 \mu \mathrm{L}$ aliquots of the reaction mixture were removed quickly before recapping the vial. The aliquots were added to $150 \mu \mathrm{L}$ of deionized water and allowed to cool further for about 1 min before the procedural standard sample preparation. Panel C: In a $10 \mathrm{~mL}$ volumetric flask was dissolved $15 \mathrm{mg}$ of Z-OMPD, 4, in $0.1 \mathrm{M}$ hydrochloric acid and filled to the mark. After immediate thorough mixing, the solution was transferred to a reaction vial with a cap and placed in a pre-heated $75^{\circ} \mathrm{C}$ heating block and allowed to react. At designated time points $100 \mu \mathrm{L}$ aliquots were removed quickly before recapping the reaction vial. The aliquots were added to $150 \mu \mathrm{L}$ of deionized water and allowed to cool further for $1 \mathrm{~min}$ before processing for analysis as previously described. Integrated peak areas were obtained using the Xcalibur 2.1 version software equipped with the Thermo-Fisher Data systems, and the plots were generated as previously described in the general procedures.<smiles>CC(CC(=O)C(=O)O)C(=O)O</smiles>

(Z)-OMPD,4<smiles>C=CCCCCCCCCCCCCCCCCCCCCCCC(=O)O</smiles>

(Z)-CHPD,8

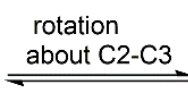<smiles>CC(=CC(=O)C(=O)O)C(=O)O</smiles>

(Z)-OMPD,4

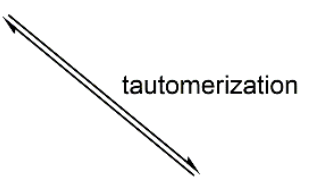

4-MEOG, 6

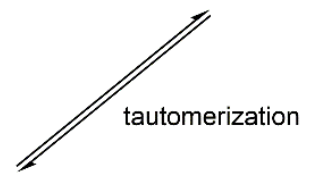<smiles>CC(=CC(=O)C(=O)O)C(=O)O</smiles>

(E)-OMPD,5
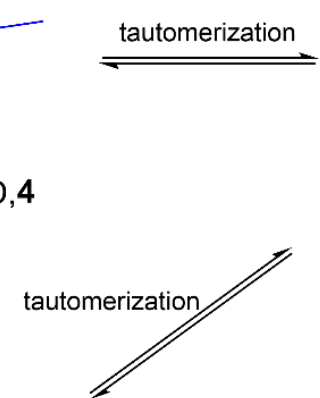<smiles>C=C(C=C(O)C(=O)O)C(=O)O</smiles>

(E)-CHPD, 7<smiles>C=C(/C=C(/O)C(=O)O)C(=O)O[14CH3]</smiles>

(E)-CHPD, 7

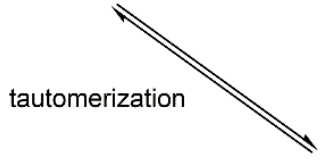

rotation about $\mathrm{C} 2-\mathrm{C} 3$

(Z)-CHPD,8

Scheme S1. Isomerization among all five isomers of OMPD via keto-enol tautomerization. 


\section{Syntheses of HMOG- disodium salt.}

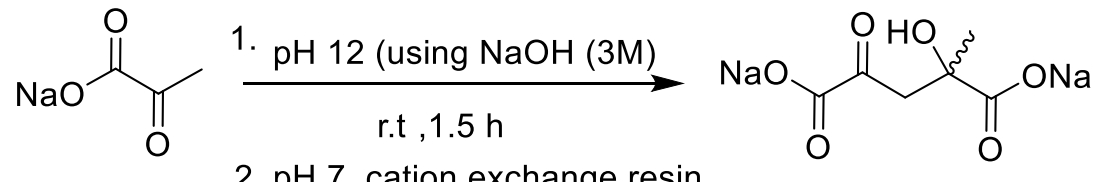

2. $\mathrm{pH} 7$, cation exchange resin

sodium pyruvate

HMOG/Parapyruvate

Synthesis of HMOG, 2, was accomplished by following the published procedure ${ }^{2,3}$ with some modification. We chose to use sodium pyruvate as the starting material instead of pyruvic acid, as the salt is known to be free of zymonic acid (see Figure S18 on page S31), condensation product, or higher polymers ${ }^{3}$. We wanted to eliminate any further polymerization during the alkaline stage of the synthesis.

Sodium pyruvate $(3 \mathrm{~g}, 27.27 \mathrm{mmol})$ was added to water $(30 \mathrm{~mL})$ in a round bottom flask and the solution was adjusted to $\mathrm{pH} 12$ via the dropwise addition of $3 \mathrm{M}$ sodium hydroxide with stirring. The reaction mixture was allowed to stir for 1.5 hour at room temperature before the adjustment to $\mathrm{pH} 7$ via the addition of $\mathrm{AG} 50 \mathrm{~W}-\mathrm{X} 4 \mathrm{H}^{+}$hydrogen form (100 -200 mesh) resin. The mixture was allowed to stir further for a few minutes before the resin was filtered off. The mixture was concentrated to about 6-10 mL using rotary evaporation, and to the concentrated viscous liquid was added methanol $(54 \mathrm{~mL})$ which, with stirring, turns into a slightly white precipitate. To the mixture was added diethyl ether $(50 \mathrm{~mL})$ to form a precipitate which was stirred briefly then placed in an ice bath for $10 \mathrm{~min}$. The white solid was vacuum filtered along with washing of small portions of ether during the process. The supernatant was concentrated slightly further and subjected to another found of precipitation, vacuum filtration, and ether wash. The sticky solids were dried overnight in a vacuum desiccator to become crunchy white solids after removal of water. Combined two ppt crops (yielded 1 gram, 58 \%yield) ${ }^{1} \mathrm{H}$ NMR $\left(\mathrm{D}_{2} \mathrm{O}, 500 \mathrm{MHz}\right): \delta 1.37(\mathrm{~s}, 3 \mathrm{H}), \delta$ 3.16-3.32 (ABq. $J=48 \mathrm{~Hz}, 18 \mathrm{~Hz}, 2 \mathrm{H}$ ); ${ }^{13} \mathrm{C} \mathrm{NMR}\left(126 \mathrm{MHz}, \mathrm{D}_{2} \mathrm{O}\right.$ ) $\delta 205.70,184.82,172.06$, 76.22,51.34, 28.76. ESI-MS (-): Calculated $\mathrm{m} / \mathrm{z}=175.02$, found $\mathrm{m} / \mathrm{z}=175.04$. 
${ }^{1} \mathrm{H}$ NMR in $\mathrm{D}_{2} \mathrm{O}$
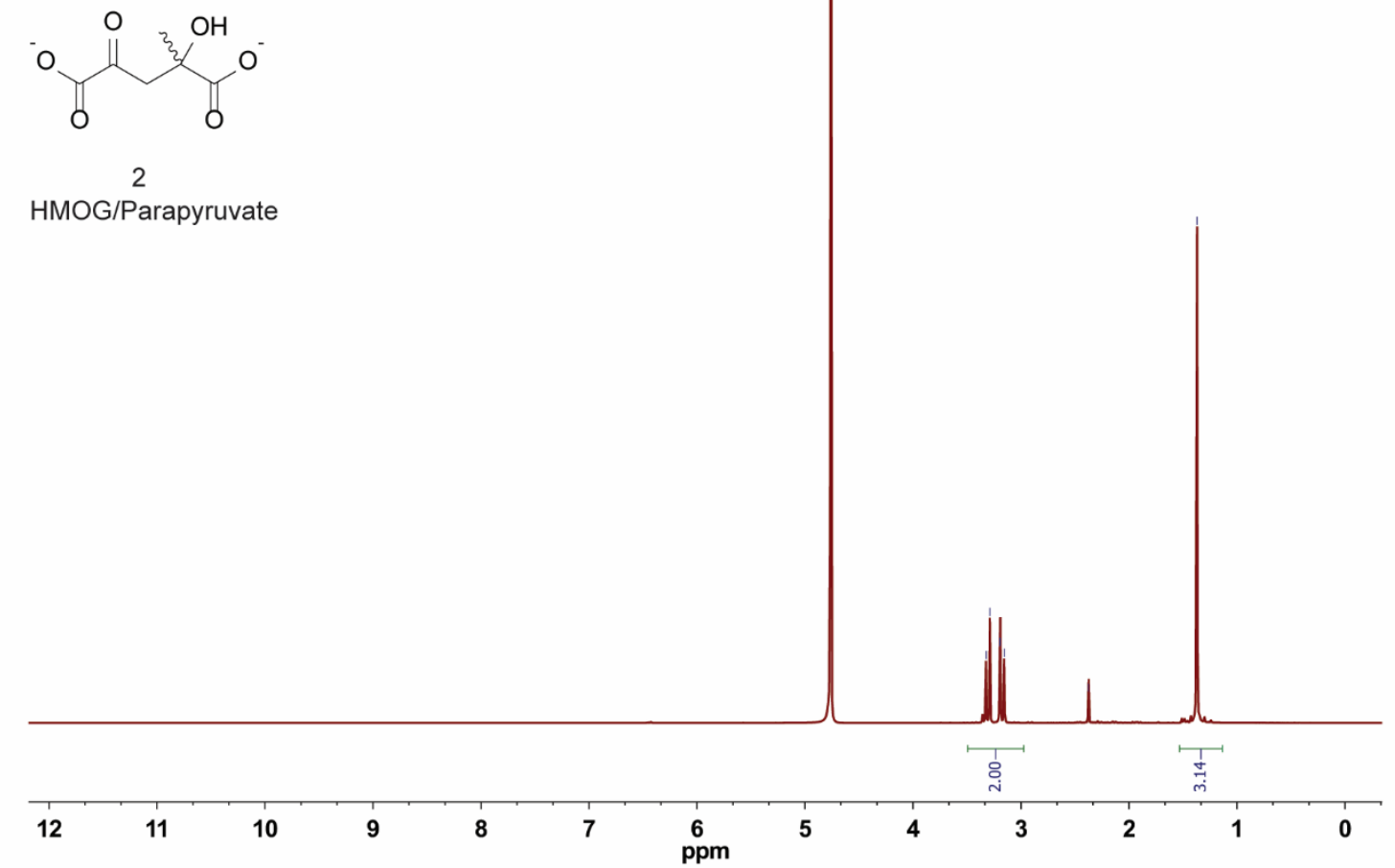

${ }^{13} \mathrm{C}$ NMR in $\mathrm{D}_{2} \mathrm{O}$
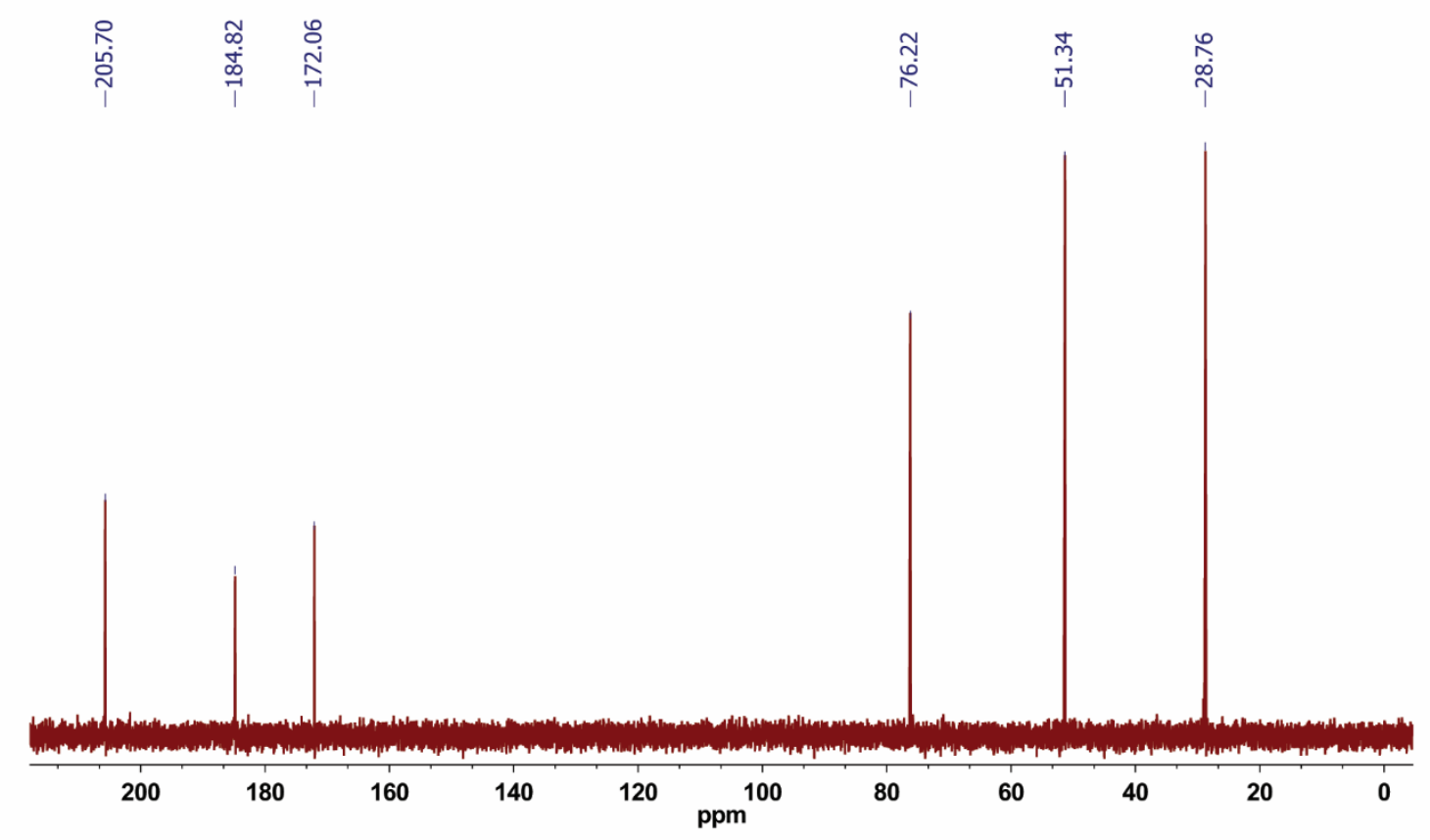

Figure S9. NMR spectra of HMOG-disodium salt 


\section{Synthesis of Methyl zymonate ester,11}

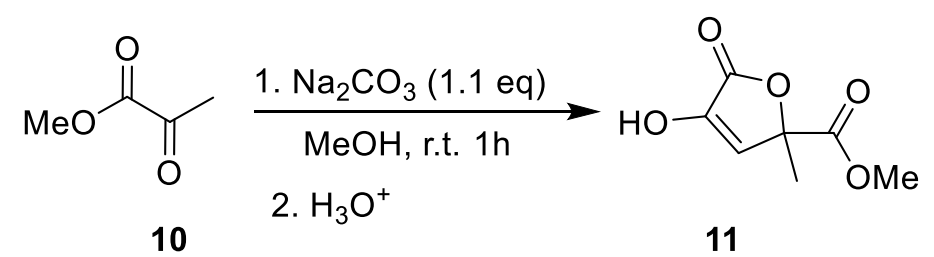

Methylpyruvate,10 (1 g, $9.8 \mathrm{mmols})$ was added to a round bottom flask containing a stirred suspension of sodium carbonate $(1.14 \mathrm{~g}, 10.78 \mathrm{mmol})$ in methanol $(196 \mathrm{~mL})$. After addition, the white suspension was allowed to react at room temperature for 1.5 hour. After monitoring by thin layer chromatography (90:10 Dichloromethane/Methanol), the reaction mixture was vacuum filtered to remove most of the inorganic salt and the supernatant was concentrated to a white solid. The crude product-carbonate solid mixture was suspended in ethyl acetate $(50 \mathrm{~mL})$ and with stirring the mixture was acidified to $\mathrm{pH} \mathrm{0-1} \mathrm{with} \mathrm{conc.} \mathrm{HCl}$ and $25 \mathrm{~mL}$ of water. The layers were transferred to a separatory funnel and the aqueous layer was extracted two more times with ethyl acetate $(2 \mathrm{X} 25 \mathrm{~mL})$, the combined organic layer was washed with brine and dried over sodium sulfate. Ethyl acetate was removed under reduced pressure leaving a light, yellow oil. The crude oil was purified by column chromatography using hexanes: ethylacetate (70:30) resulting in a pure slightly yellow colored oil $(0.742 \mathrm{~g}, 88 \%) .{ }^{1} \mathrm{H} \mathrm{NMR}\left(500 \mathrm{MHz}, \mathrm{CDCl}_{3}\right) \delta, 6.99$ (br s, 1H), $6.25(\mathrm{~s}, 1 \mathrm{H}), 3.72(\mathrm{~s}, 3 \mathrm{H}),(1.66 \mathrm{~s}, 3 \mathrm{H}) .{ }^{13} \mathrm{C} \mathrm{NMR}\left(126 \mathrm{MHz}, \mathrm{CDCl}_{3}\right) \delta$ 169.52, 169.24 , 142.79, 119.70, 83.12, 53.34, 22.66. ESI-MS (-): Calculated $\mathrm{m} / \mathrm{z}=171.03$, found $\mathrm{m} / \mathrm{z}=171.04$. 
${ }^{1} \mathrm{H} \mathrm{NMR}$ in $\mathrm{CDCl}_{3}$

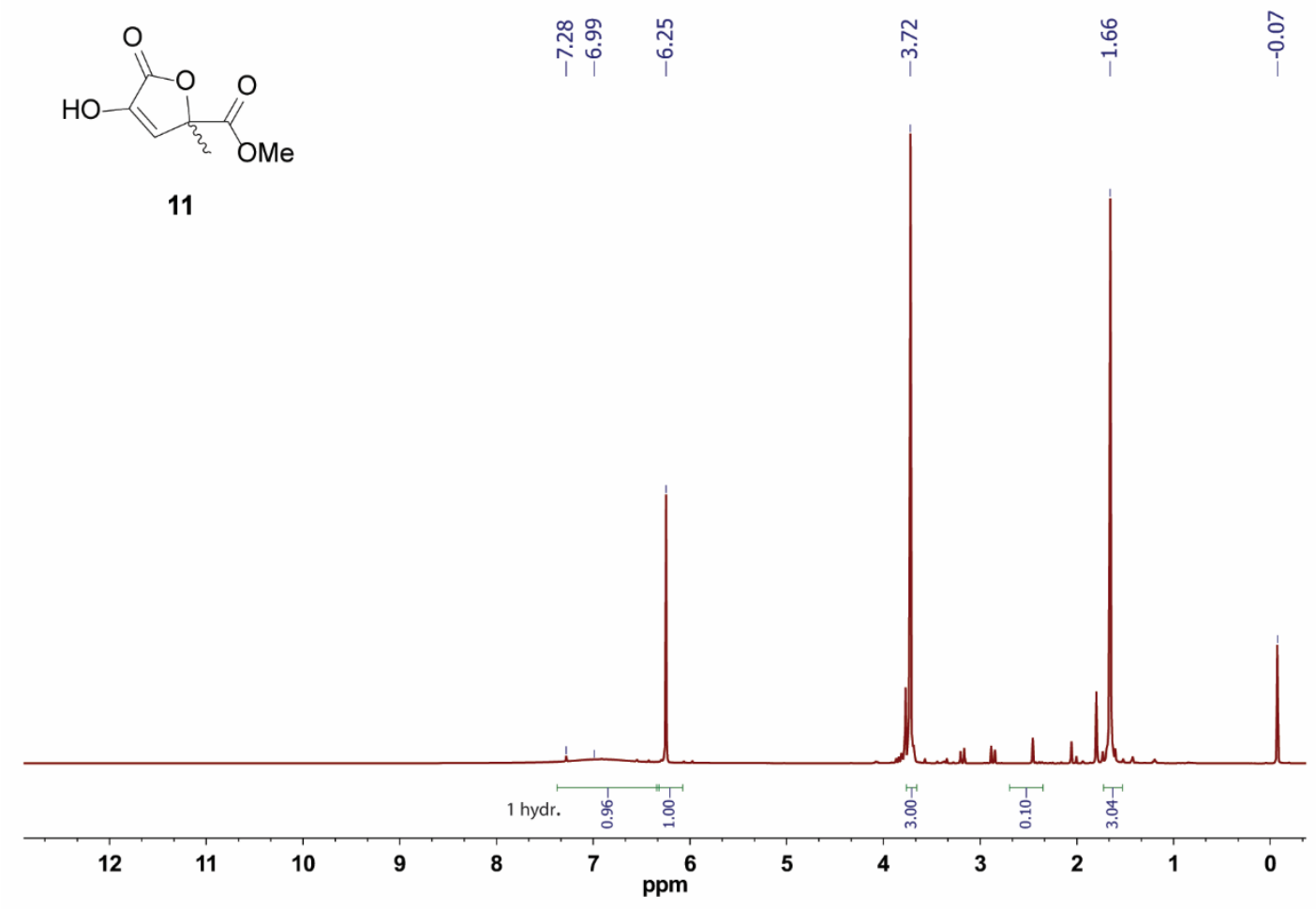

${ }^{13} \mathrm{C} \mathrm{NMR}$ in $\mathrm{CDCl}_{3}$

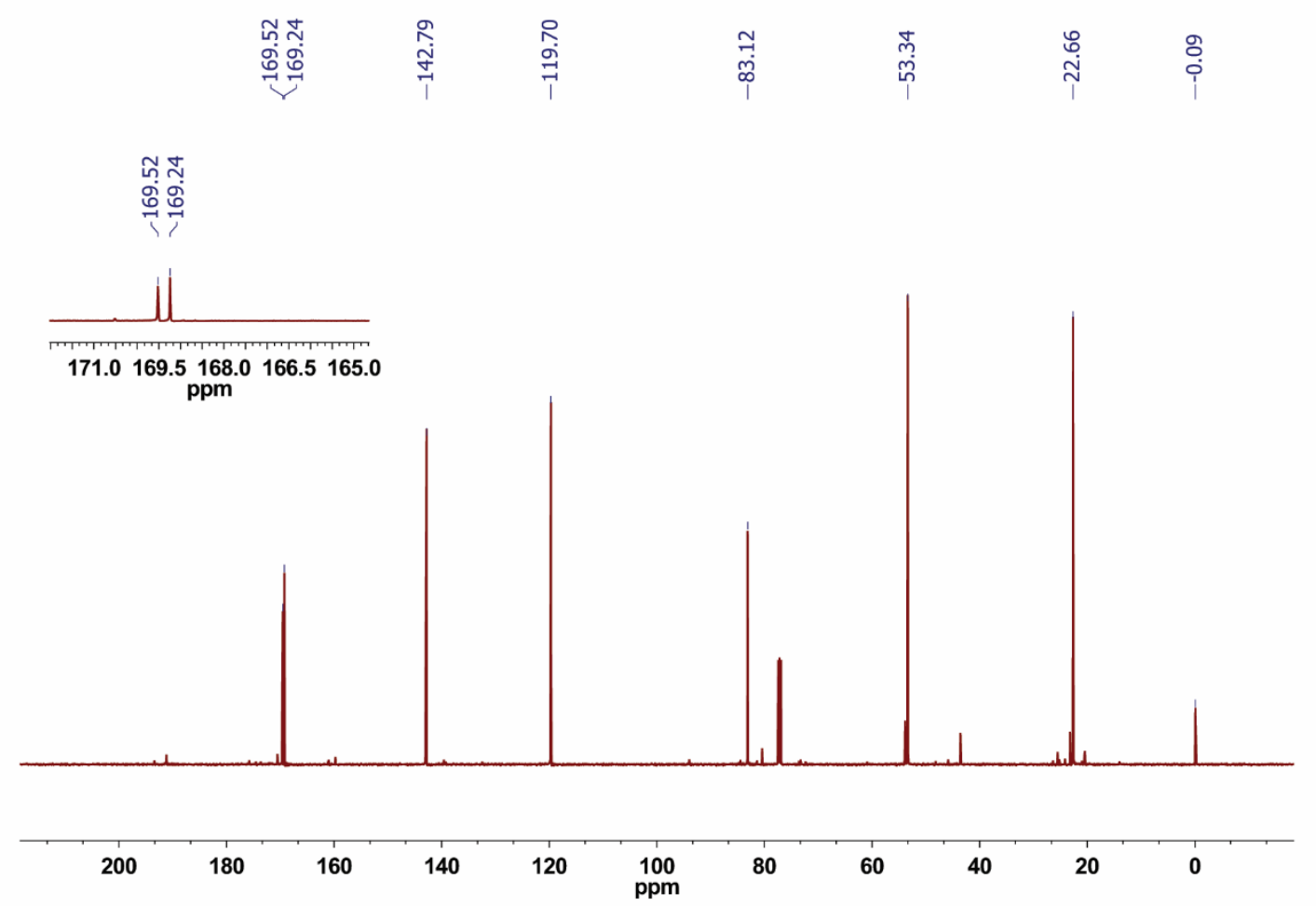

Figure S10. NMR spectra of methyl zymonate, 11 


\section{Synthesis of Zymonic acid from hydrolysis of 11}<smiles>COC(=O)C1(C)C=C(O)C(=O)O1</smiles>

11

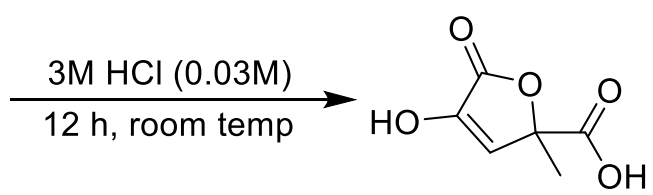

3

Methyl zymonate,11 $(0.5146 \mathrm{~g}, 2.99 \mathrm{mmol})$ was added to a solution of $3 \mathrm{M} \mathrm{HCl}(96.90 \mathrm{~mL})$ and the reaction mixture was stirred at room temperature overnight. After monitoring by thin layer chromatography (90:10 Dichloromethane/Methanol), the reaction mixture was extracted in ethyl acetate $(50 \mathrm{~mL})$ and extracted two more times with $30 \mathrm{~mL}$ of ethyl acetate. The organic layers were combined and dried over sodium sulfate. Solvent was removed by reduced pressured to afford a light tan viscous oil (mass of crude was $0.310 \mathrm{~g}, 65 \%$ ). Purification was not pursued as crude product NMR matched crystalline zymonic acid obtained from refrigerated bottles of commercial source of pyruvic acid (see comparison below). ${ }^{1} \mathrm{H}$ NMR (500 MHz, DMSO-d 6 ) $\delta$, 13.48 (br s, $1 \mathrm{H}$ ), 10.72 (br s, 1H), 6.29 (s, 1H), 1.57 (s, 3H). ${ }^{13} \mathrm{C}$ NMR (126 MHz, DMSO-d 6 ) $\delta$ $170.49,168.26,143.15,119.27,81.76,22.50$. ESI-MS (-): Calculated $\mathrm{m} / \mathrm{z}=157.03$, found $\mathrm{m} / \mathrm{z}=$ 157.04. 
${ }^{1} \mathrm{H}$ NMR in DMSO-d

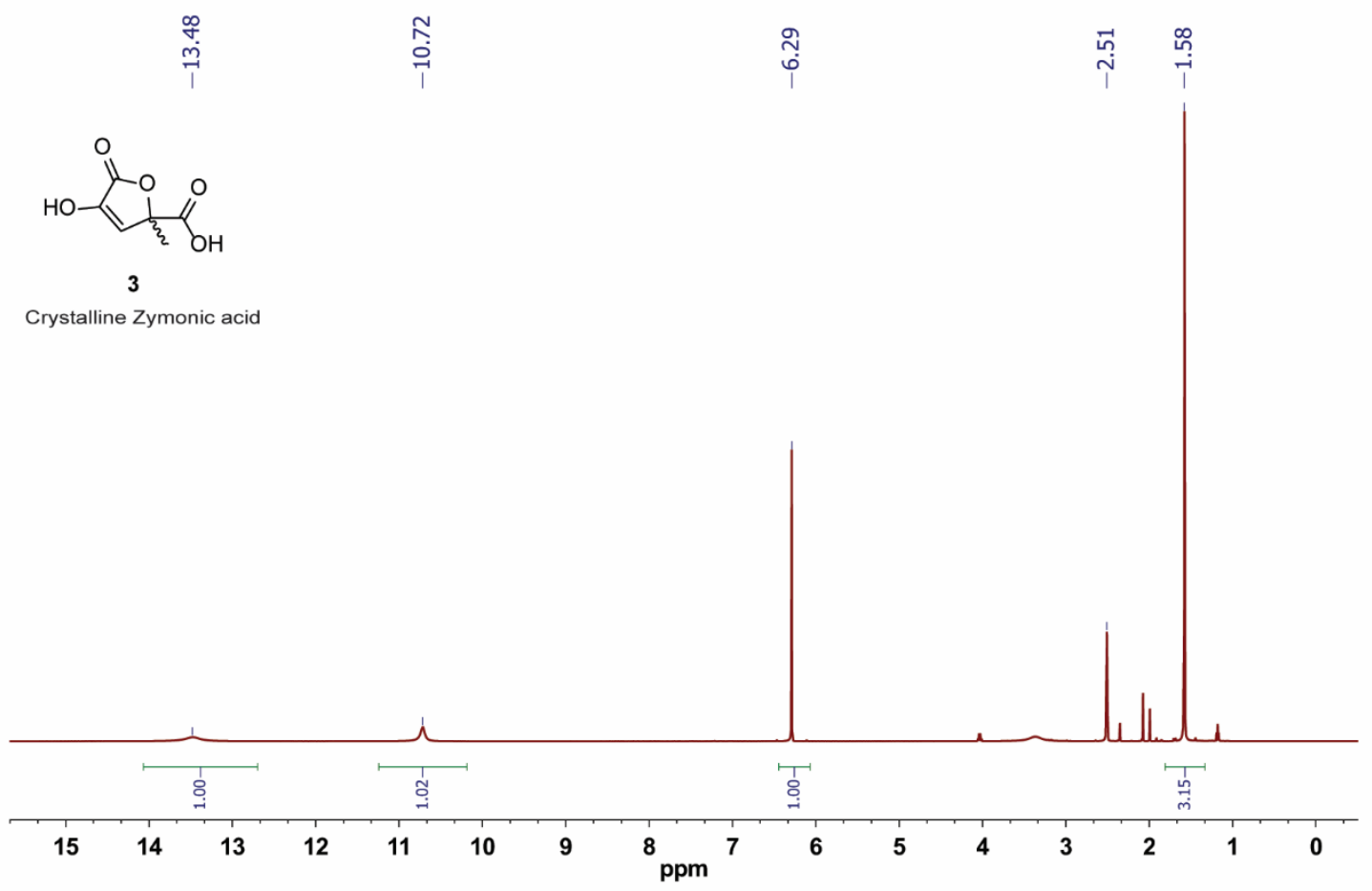

${ }^{13} \mathrm{C}$ NMR in DMSO-d6

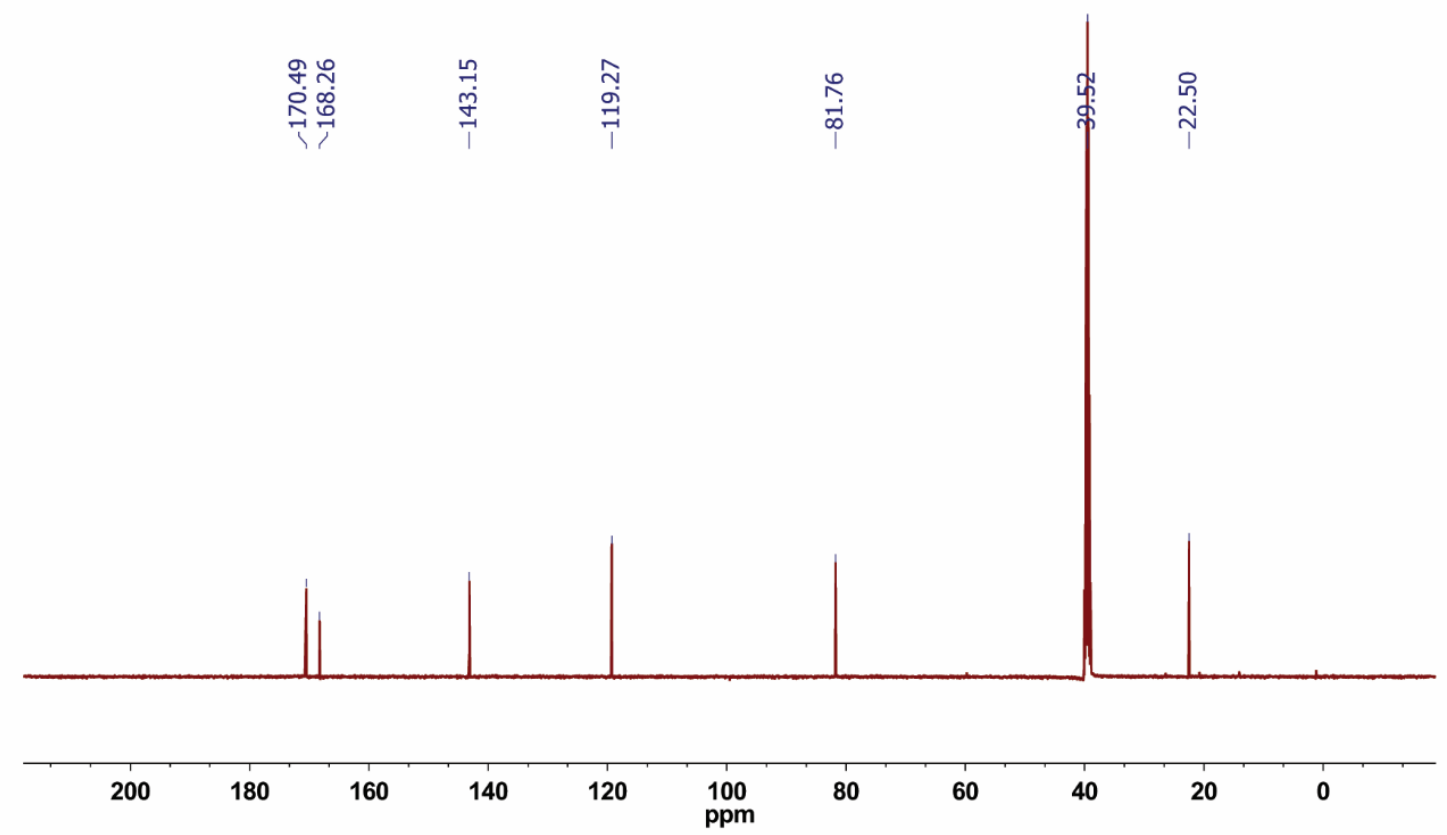

Figure S11. NMR spectra of crystalline zymonic acid, 3. 
${ }^{1} \mathrm{H}$ NMR in DMSO-d

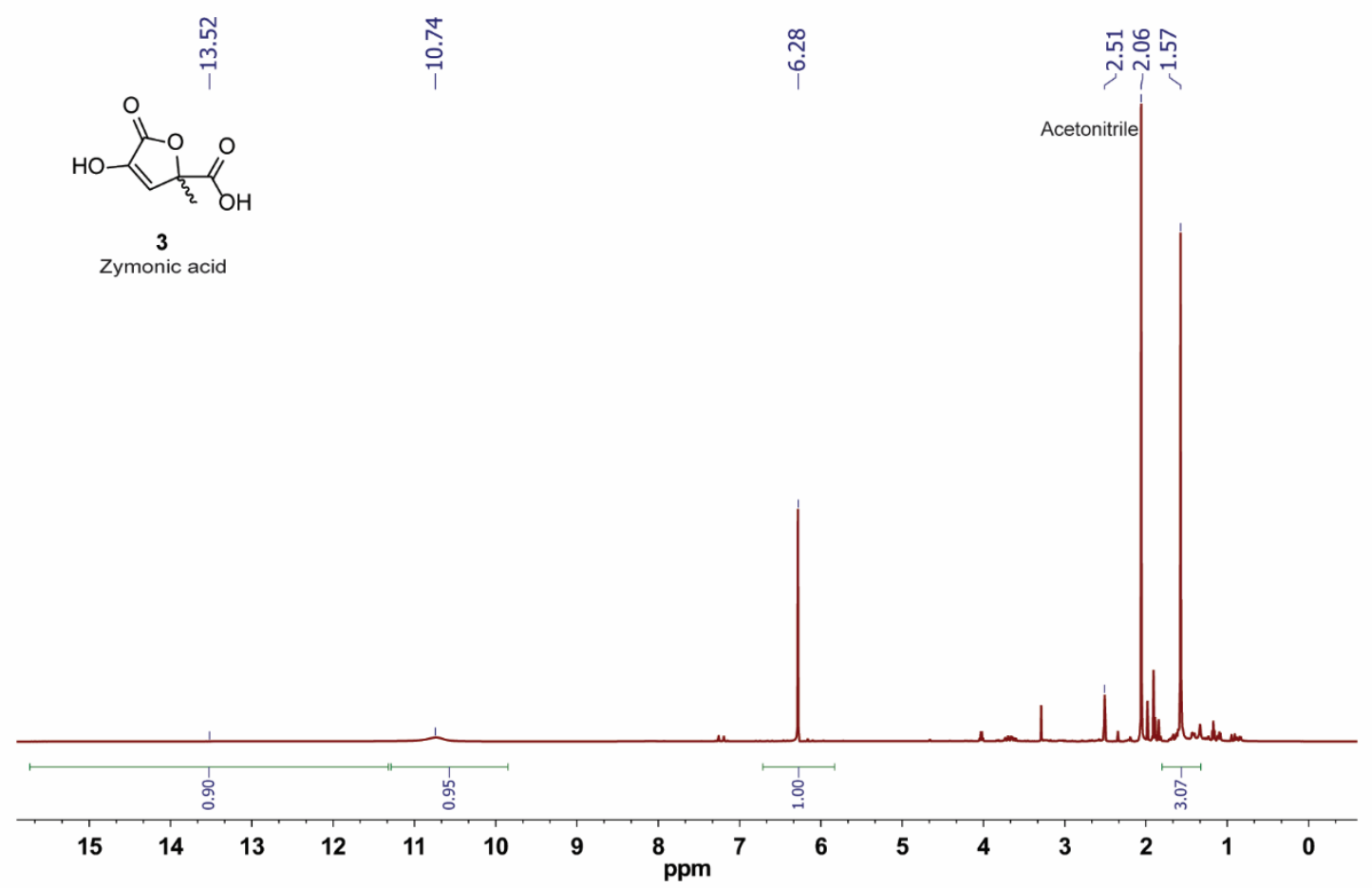

${ }^{13} \mathrm{C}$ NMR in DMSO-d 6

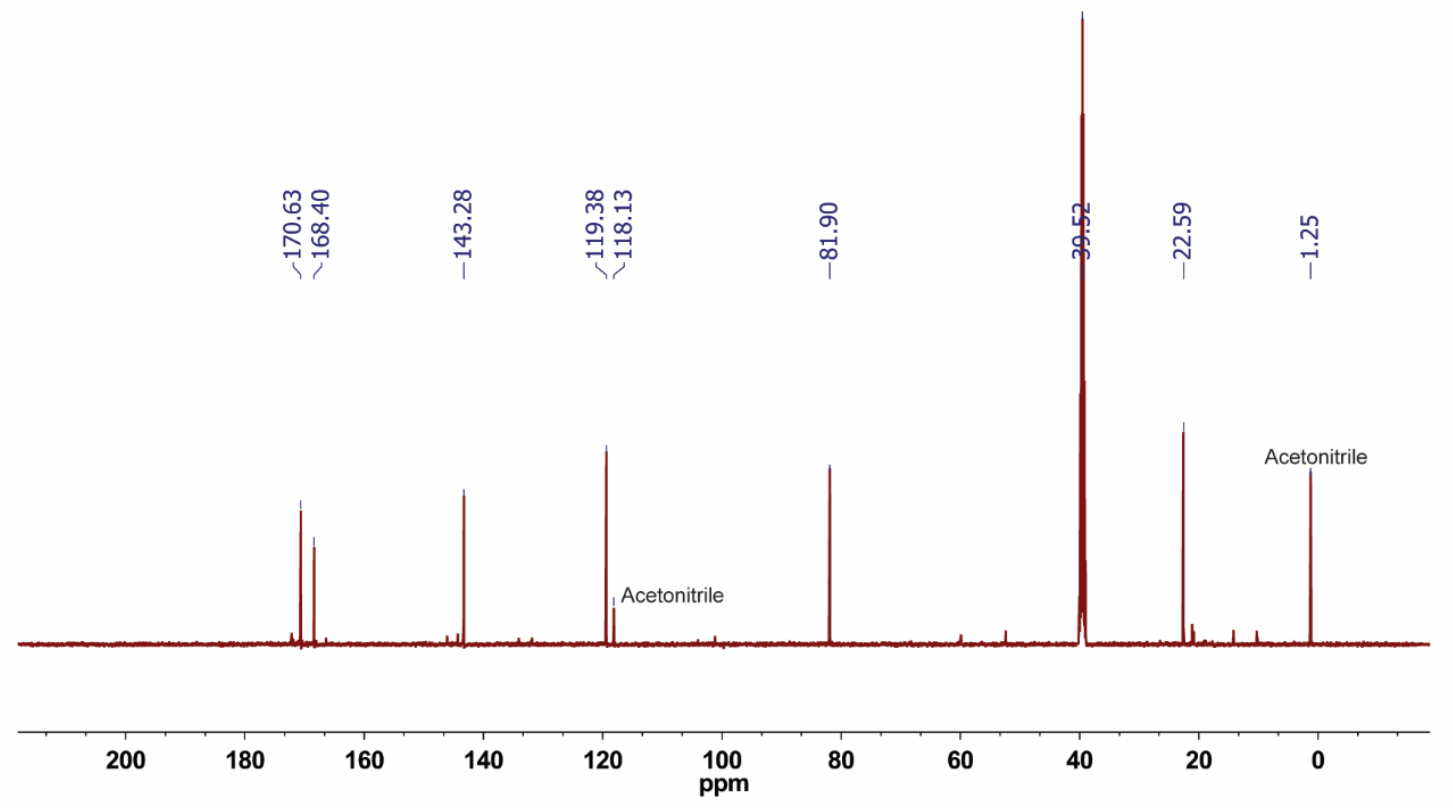

Figure S12. NMR spectra of zymonic acid from hydrolysis of 11 


\section{Synthesis of 12 from 11}<smiles>COC(=O)COC(=O)COC(=O)C(=O)/C=C(/C)C(=O)OC</smiles>

Methyl zymonate,11 (0.850 g, 4.94 mmoles) was added to a round bottom flask containing a premixture of sodium carbonate $(0.576 \mathrm{~g}, 5.43 \mathrm{mmol})$ in methanol $(247 \mathrm{~mL})$ and the suspension was stirred at $40^{\circ} \mathrm{C}$ for 36 hours. Monitoring by thin layer chromatography (90:10 Dichloromethane: Methanol) revealed the spot to spot conversion that correlated with an observable yellow color of the enol tautomer product that develops in the reaction mixture. Upon completion, the reaction mixture was vacuum filtered warm, and the yellow supernatant was concentrated to yellow-white solid. Purification by $\mathrm{pH}$-controlled liquid-liquid extraction: Initial attempts to purify the crude mixture by column chromatography was found to promote a mixture of species so the following method was identified as the best route. The crude product-carbonate solid mixture was suspended in ethyl acetate $(30 \mathrm{~mL})$ and $20 \mathrm{~mL}$ of water and with stirring the mixture was acidified dropwise to $\mathrm{pH} 5.5-6$ fairly quickly with $3 \mathrm{M} \mathrm{HCl}$. The layers were transferred to a separatory funnel and the organic layer removed, the aqueous layer was washed two more times with ethyl acetate $(2 \times 30 \mathrm{~mL})$, and the organic layer combined and labeled as 'organic A'. The aqueous layer was acidified to $\mathrm{pH} \mathrm{0-1} \mathrm{using} \mathrm{concentrated} \mathrm{hydrochloric} \mathrm{acid} \mathrm{with} \mathrm{stirring} \mathrm{in} \mathrm{the} \mathrm{original} \mathrm{round} \mathrm{bottom}$ flask and then transferred back to separatory funnel and $20 \mathrm{~mL}$ brine and $30 \mathrm{~mL}$ of ethyl acetate were added and mixed and layers separated. The aqueous layer was extracted two more times with $30 \mathrm{~mL}$ portions of ethyl acetate and the organic layers were combined and labeled as 'organic B' and dried over sodium sulfate. Organic B contained the product, a yellow orange oil $(0.572 \mathrm{~g}$, $67 \%$ ). ${ }^{1} \mathrm{H}-\mathrm{NMR}\left(500 \mathrm{MHz}, \mathrm{DMSO}-\mathrm{d}_{6}\right) \delta$ 13.67, (bs, $\left.1 \mathrm{H}\right), 7.27$ (q, J = $\left.1.5 \mathrm{~Hz}, 1 \mathrm{H},\right), 3.29(\mathrm{~s}, 3 \mathrm{H})$, $1.89(\mathrm{~d}, J=1.5 \mathrm{~Hz}, 3 \mathrm{H}) .{ }^{13} \mathrm{C}$ NMR $(126 \mathrm{MHz}$, DMSO-d 6 ) $\delta 171.37,166.73,144.67,134.37,104.33$, 52.69, 10.65. ESI-MS (-): Calculated $\mathrm{m} / \mathrm{z}=171.03$, found $\mathrm{m} / \mathrm{z}=171.14$. 
${ }^{1} \mathrm{H}$ NMR in DMSO-d
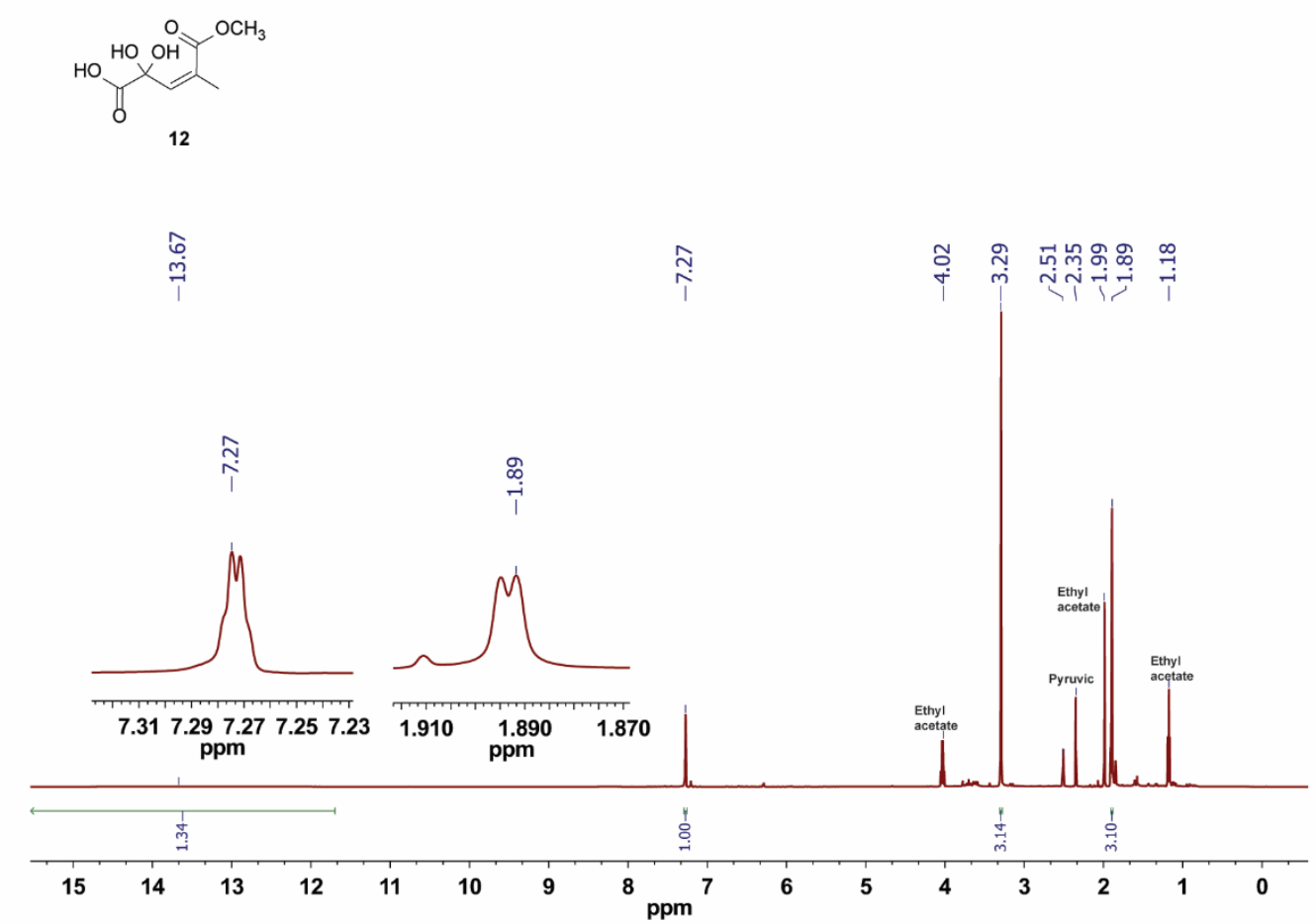

${ }^{13} \mathrm{C}$ NMR in DMSO-d 6

$$
\left.\right|_{12} ^{\mathrm{HO}} \mathrm{CH}_{\mathrm{C}}^{\mathrm{O}} \mathrm{OCH}_{\mathrm{E}}^{\mathrm{O}}
$$

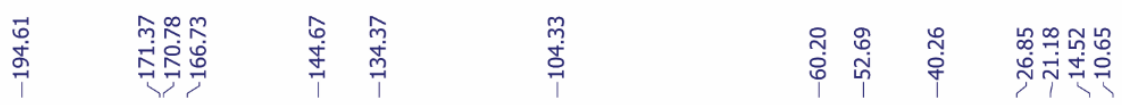

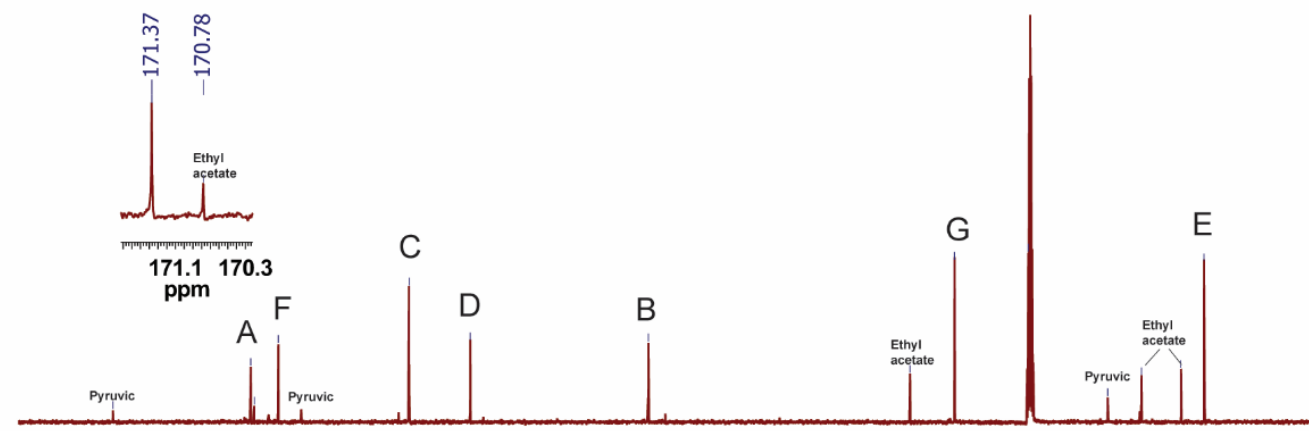

\begin{tabular}{|c|c|c|c|c|c|c|c|c|c|c|}
\hline 200 & 180 & 160 & 140 & 120 & $\begin{array}{r}100 \\
\mathrm{ppm}\end{array}$ & 80 & 60 & 40 & 20 & 0 \\
\hline
\end{tabular}

Figure S13. NMR spectra of 12 in DMSO-d6 


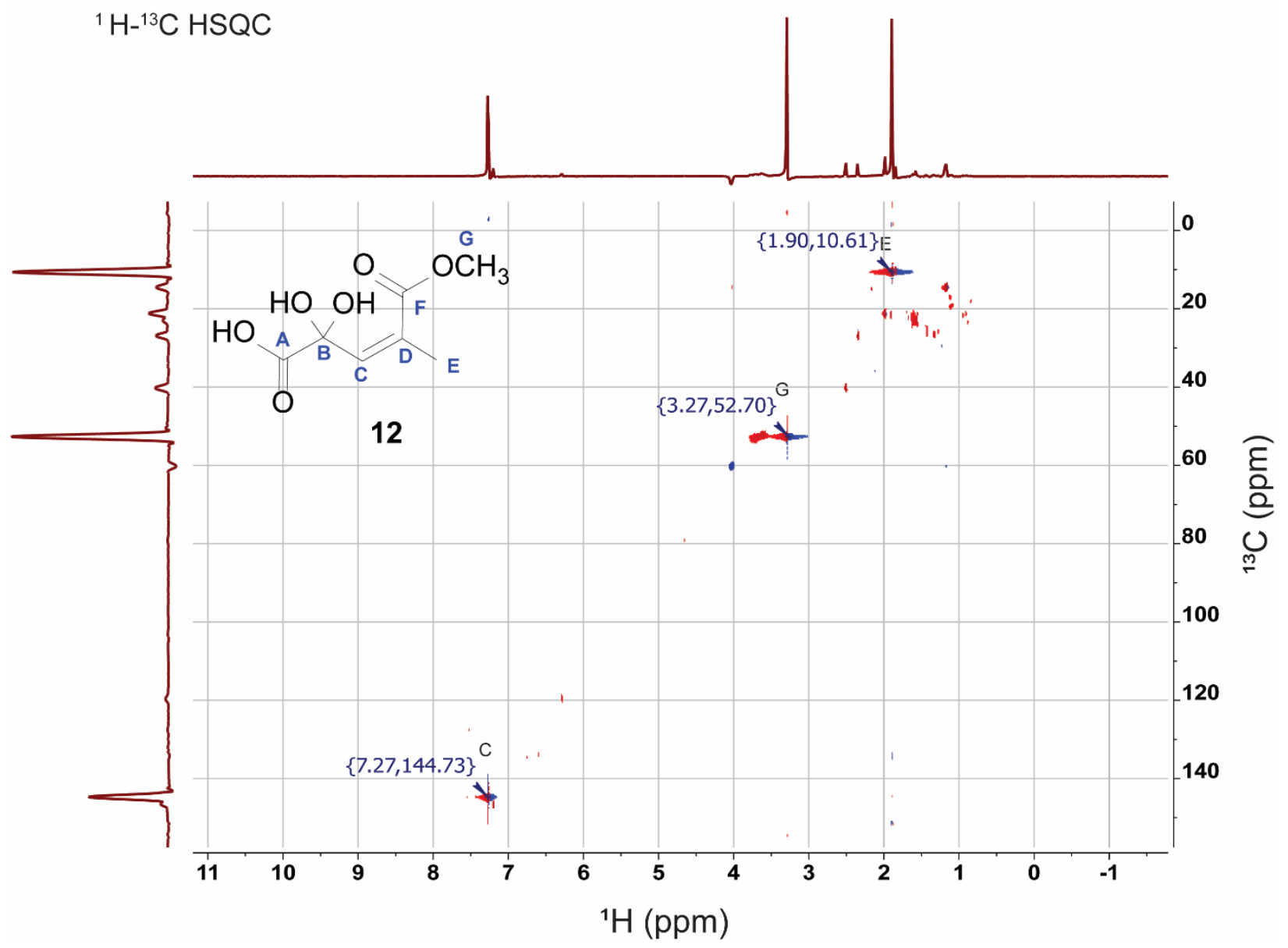

Figure S14. ${ }^{1} \mathrm{H}-{ }^{13} \mathrm{C}$ HSQC NMR spectra of 12 in DMSO-d6 


\section{Synthesis of 12 from Methyl Pyruvate}

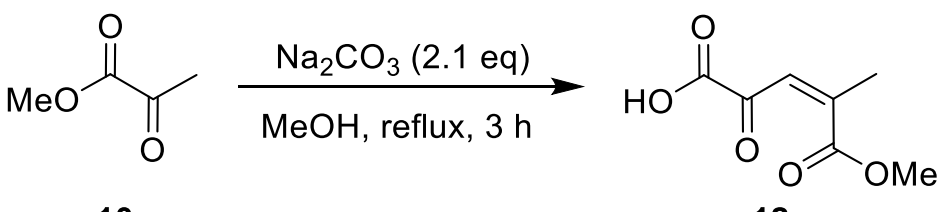

10

12

Methyl pyruvate,10 (5 g, 48.98 mmoles) was added to warmed solution of sodium carbonate (11 $\mathrm{g}, 103 \mathrm{mmol})$ in methanol $(272 \mathrm{~mL})$ and the suspension was stirred and refluxed for 3 hours. Monitoring by thin layer chromatography (95:5 dichloromethane: methanol) showed the expected initial formation of methylzymonate (the lactone formed upon acidification of the reaction mixture for TLC containing presumably dimethylparapyruvate) as a faster moving spot which disappeared as the appearance of a slower moving spot ( $\mathrm{Rf} .0 .13$ ) became more prominent upon extended reflux and an observable strong yellow-orange color developed in the reaction mixture. Upon completion, the reaction mixture was vacuum filtered and warmed to removed solid white carbonate and the orange supernatant was concentrated to an orange-white solid. Purification by $\mathrm{pH}$-controlled liquid-liquid extraction: Initial attempts to purify the crude mixture by column chromatography was found to promote a mixture of species so the following method was identified to be the best route. The crude product-carbonate solid mixture was suspended in ethyl acetate $(100 \mathrm{~mL})$ and $50 \mathrm{~mL}$ of water and with stirring the mixture was quickly acidified to $\mathrm{pH} 5.5-6$ by the dropwise addition of conc. $\mathrm{HCl}$. Upon mild acidification the color of the solution becomes less orange and takes on a yellow color. The layers were transferred to a separatory funnel and the organic layer removed, the aqueous layer was washed two more times with ethyl acetate $(2 \times 20$ $\mathrm{mL}$ ), and the organic layer combined and labeled as 'organic A'. The aqueous layer was acidified to $\mathrm{pH} \mathrm{0-1} \mathrm{with} \mathrm{stirring} \mathrm{in} \mathrm{the} \mathrm{original} \mathrm{round} \mathrm{bottom} \mathrm{flask} \mathrm{and} \mathrm{then} \mathrm{transferred} \mathrm{back} \mathrm{to} \mathrm{the} \mathrm{separatory}$ funnel and $50 \mathrm{~mL}$ of brine and $100 \mathrm{~mL}$ of ethyl acetate was added and mixed and layers separated. The aqueous layer was extracted two more times with $100 \mathrm{~mL}$ portions of ethyl acetate and the organic layers were combined and labeled as 'organic B' and dried over sodium sulfate. Organic B contained the product, a yellow-orange oil (1.89 g, $45 \%)$. ${ }^{1} \mathrm{H}$ NMR $(500 \mathrm{MHz}, \mathrm{CDCl} 3)$ $\delta 6.98(\mathrm{br}, \mathrm{s} 3 \mathrm{H}), 6.90(\mathrm{q}, J=1.5 \mathrm{~Hz}, 1 \mathrm{H}),, 3.47(\mathrm{~s}, 3 \mathrm{H}), 2.01(\mathrm{~d}, \mathrm{~J}=1.7 \mathrm{~Hz}, 3 \mathrm{H}){ }^{13} \mathrm{C} \mathrm{NMR}(126$ $\left.\mathrm{MHz}_{\mathrm{CDCl}}\right) \delta 170.59,168.11,142.15,135.84,103.26,52.92,10.74$. ESI-MS (-): Calculated m/z $=171.03$, found $\mathrm{m} / \mathrm{z}=171.11$. 
${ }^{1} \mathrm{H} \mathrm{NMR}$ in $\mathrm{CDCl}_{3}$
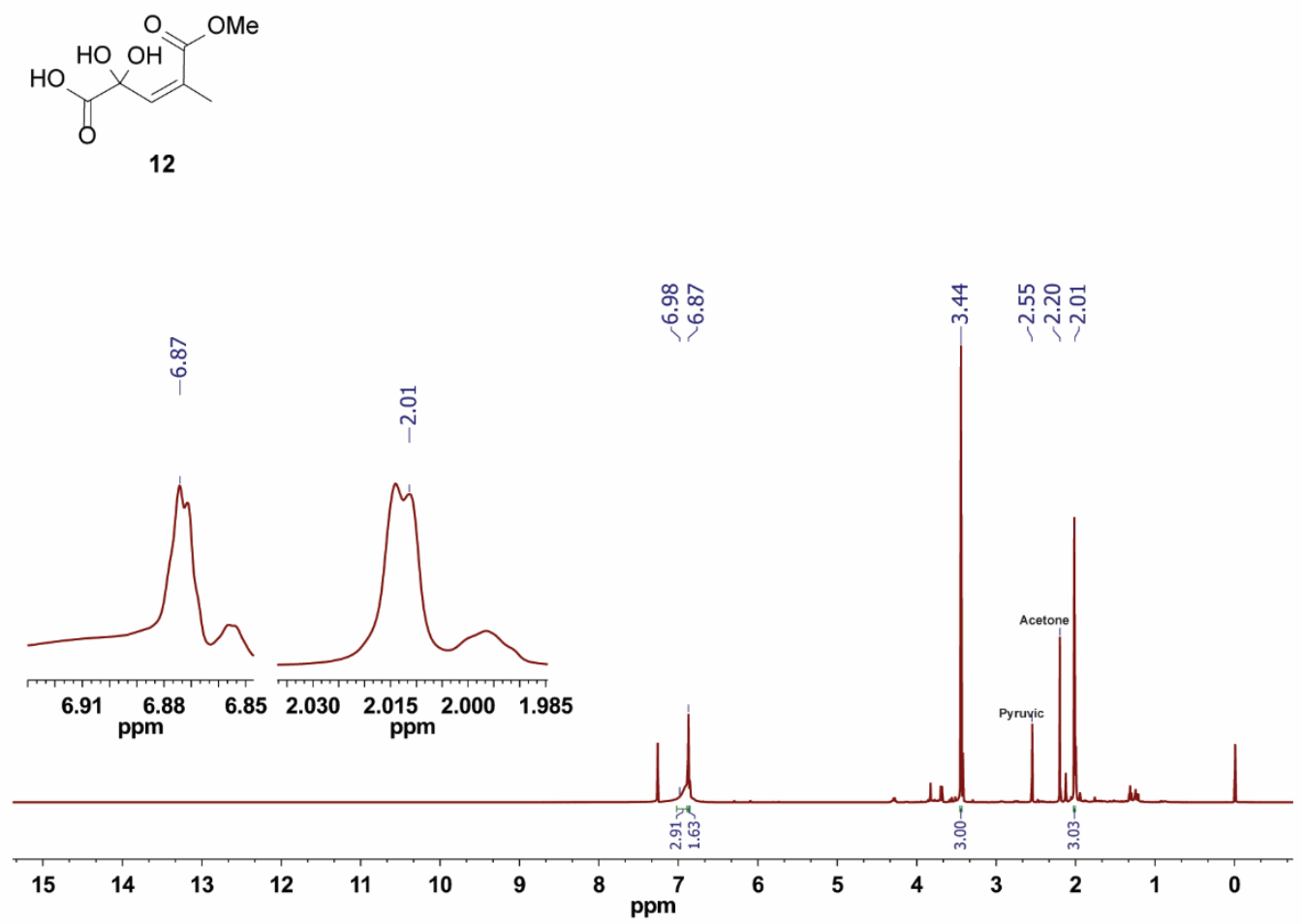

${ }^{13} \mathrm{C} \mathrm{NMR}$ in $\mathrm{CDCl}_{3}$

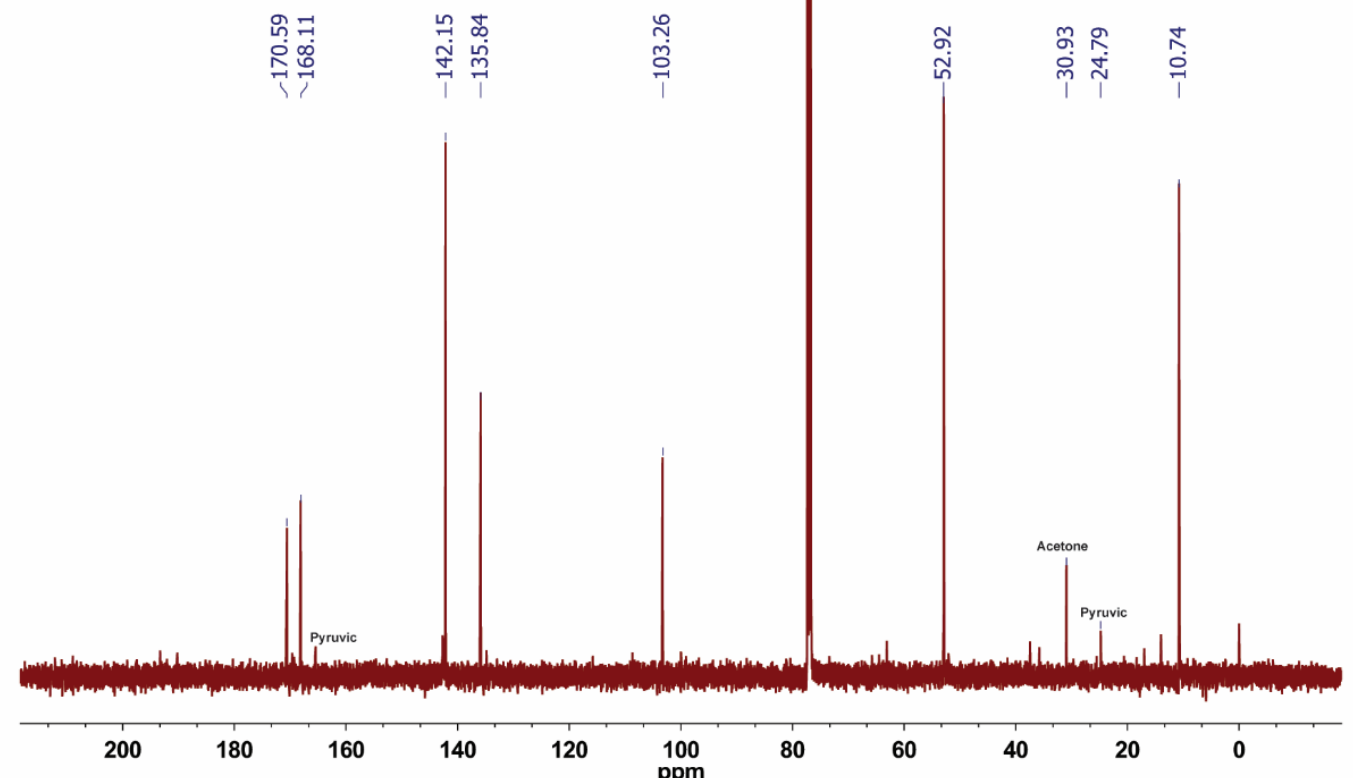

Figure S15. NMR spectra of 12 in $\mathrm{CDCl}_{3}$ 


\section{Synthesis of Z-OMPD from hydrolysis of 12}<smiles>COC(=O)/C(C)=C/C(=O)C(=O)O</smiles>

Monoester ,12, (400 mg, $2.32 \mathrm{mmol})$ was added to a solution of $3 \mathrm{M} \mathrm{HCl}(116 \mathrm{~mL})$ and the reaction mixture was stirred with heating at $65^{\circ} \mathrm{C}$ for three hours with monitoring by thin layer chromatography $(80: 20 \mathrm{DCM}: \mathrm{MeOH}$, with $<0.1 \%$ trifluoroacetic acid (TFA) added to mobile phase). Upon completion, the mixture was added to $80 \mathrm{~mL}$ of ethyl acetate in a separatory funnel , mixed, and the layers were separated. The aqueous layer was extracted two more times with 30 $\mathrm{mL}$ portions of ethyl acetate, and the combined organic layer was washed with brine and dried over sodium sulfate. Solvent was removed by reduced pressure to afford a yellow orange thick viscous oil (mass of crude was $0.357 \mathrm{~g}$,). Purification was not pursued as previous attempts resulted in a less pure product. The acetic acid in the NMR spectra below likely results from the oxidation of pyruvic acid under the reaction conditions and based on relative integration between acetic acid, the yield of Z-OMPD is determined to be $49 \%$. ${ }^{1} \mathrm{H}$ NMR (500 MHz, DMSO) $\delta 12.51$ 10.72 (br, s 2H) , 8.28 (br s $1 \mathrm{H}), 7.20(\mathrm{q}, J=1.6 \mathrm{~Hz}, 1 \mathrm{H}) ,1.85(\mathrm{~d}, J=1.6 \mathrm{~Hz}, 3 \mathrm{H}) .{ }^{13} \mathrm{C} \mathrm{NMR}(126$ $\mathrm{MHz}, \mathrm{DMSO}) \delta 172.47,168.00,146.07,131.78,101.09,10.13$. ESI-MS (-): Calculated $\mathrm{m} / \mathrm{z}=$ 157.03 , found $\mathrm{m} / \mathrm{z}=157.04$. 
${ }^{1} \mathrm{H}$ NMR in DMSO-d 6
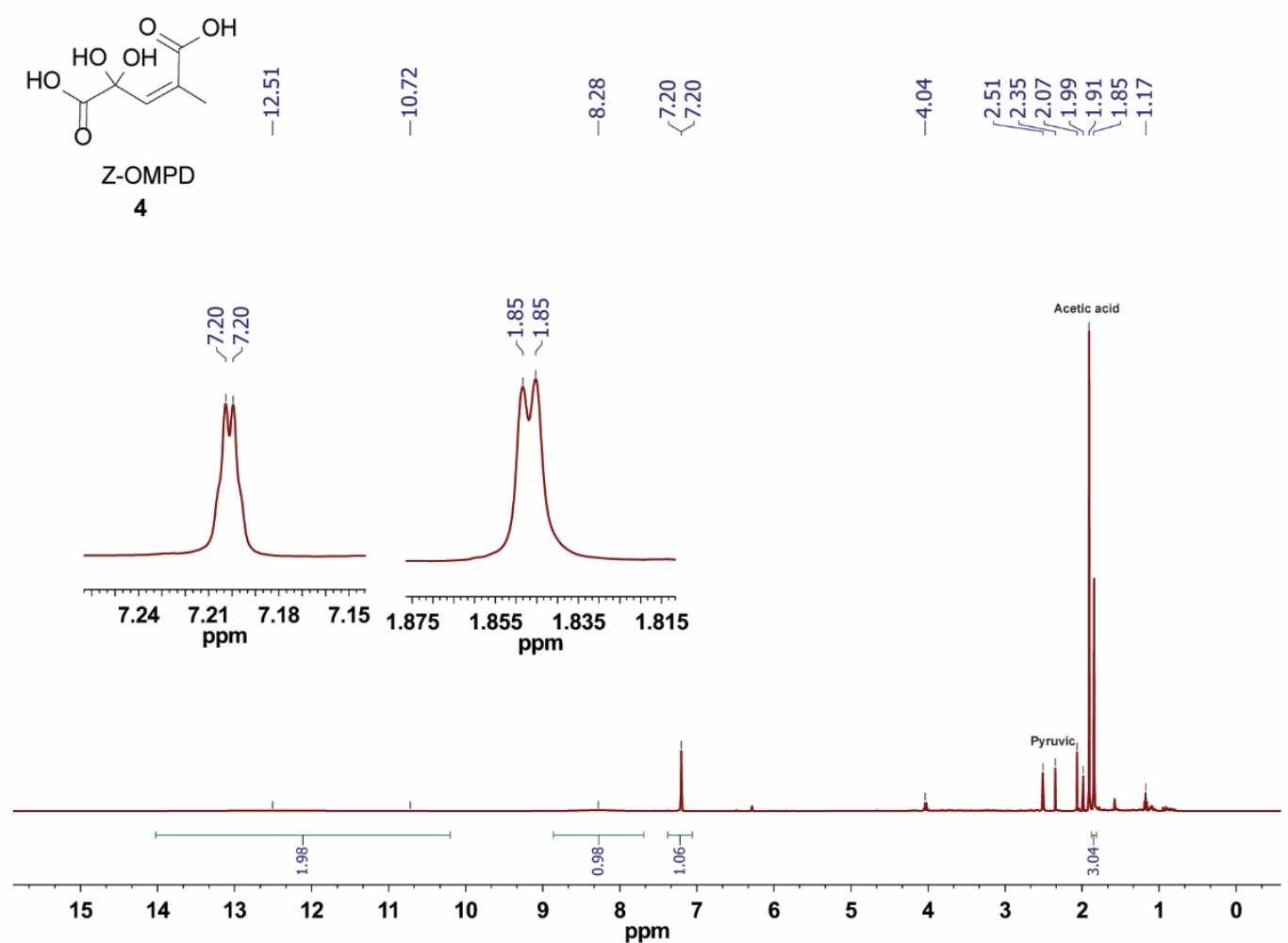

${ }^{13} \mathrm{C}$ NMR in DMSO-d $\mathrm{d}_{6}$

$$
\underbrace{\mathrm{HO} \mathrm{OH}_{\mathrm{C}}^{\mathrm{O}}}_{\mathrm{Z}-\mathrm{OMPD}}
$$

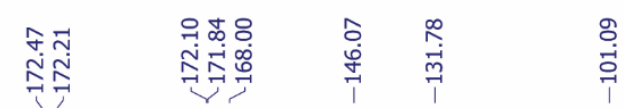
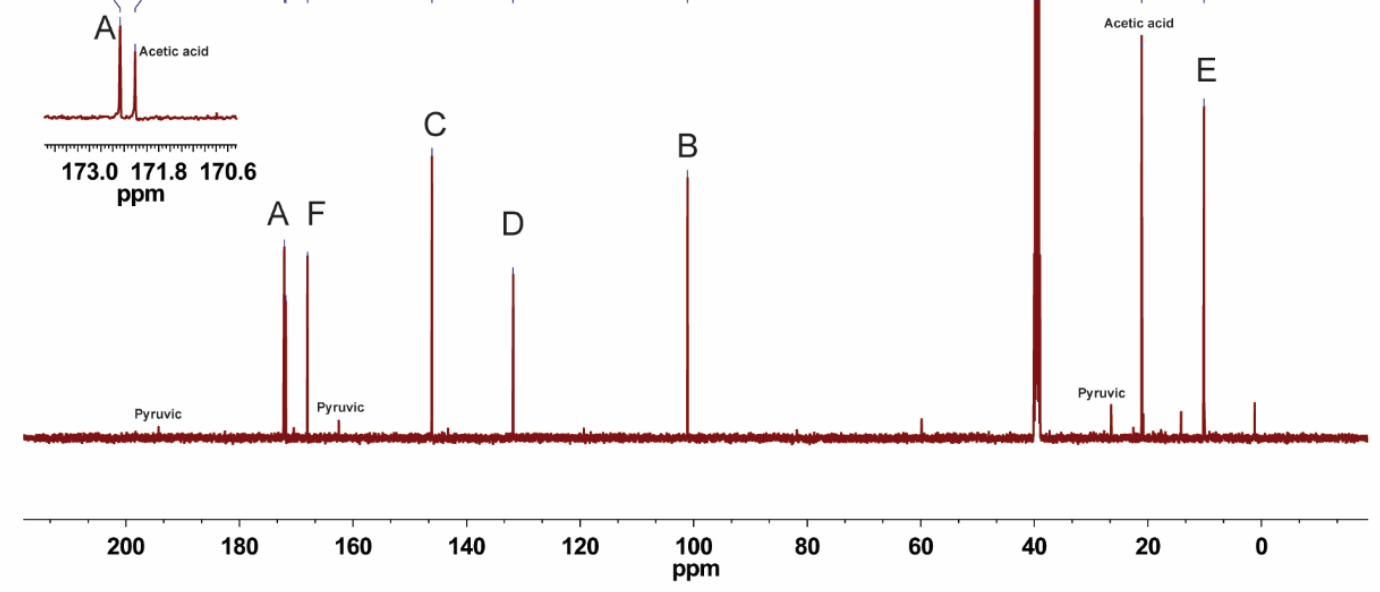

Figure S16. NMR spectra of 4 in DMSO-d6 


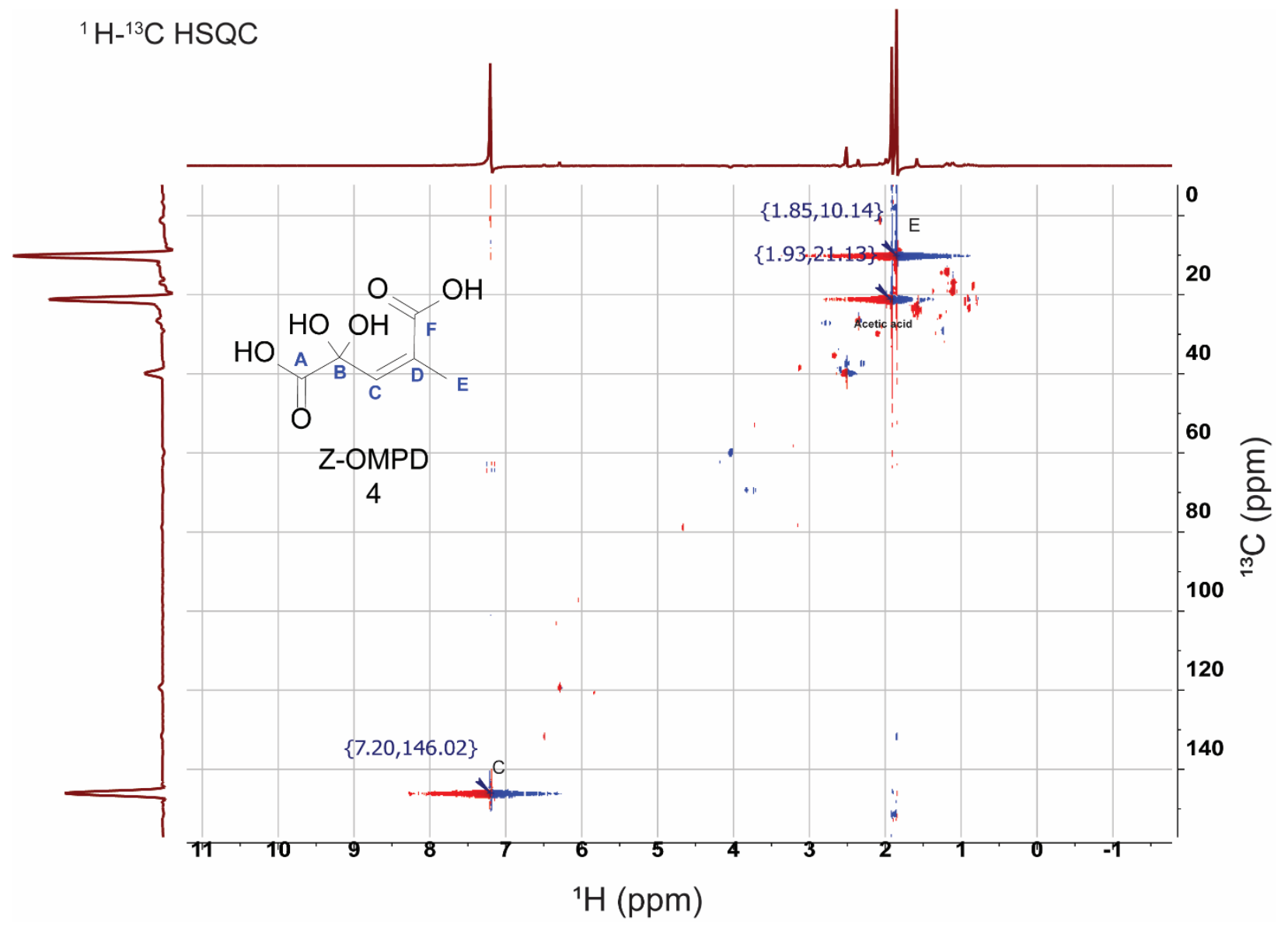

Figure S17. HSQC Spectra of 4 in DMSO-d6 
${ }^{1} \mathrm{H}$ NMR in DMSO-d

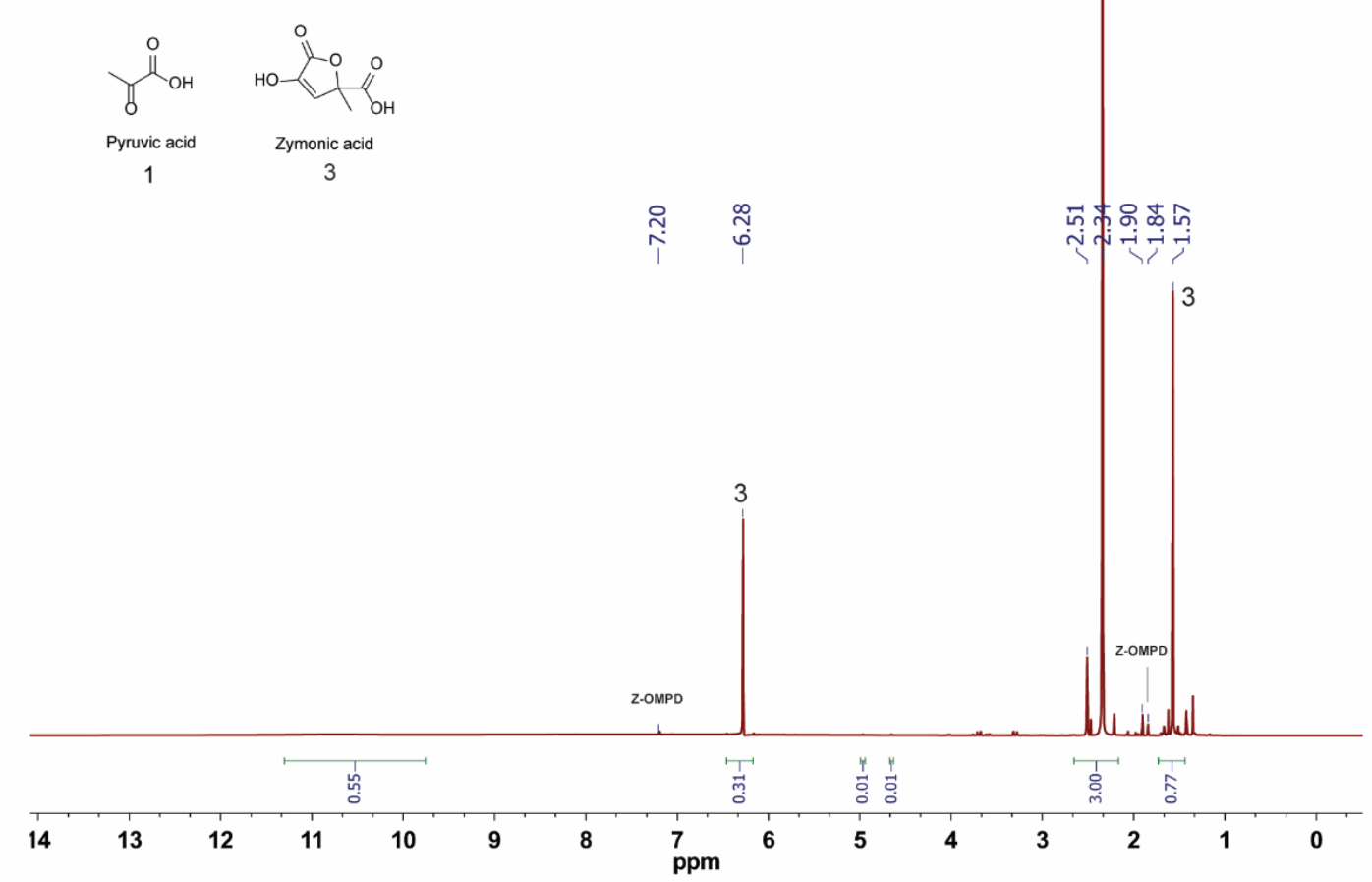

${ }^{13} \mathrm{C}$ NMR in DMSO-d6

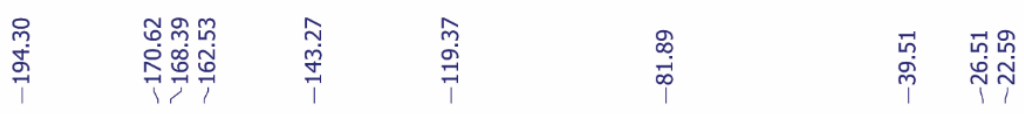

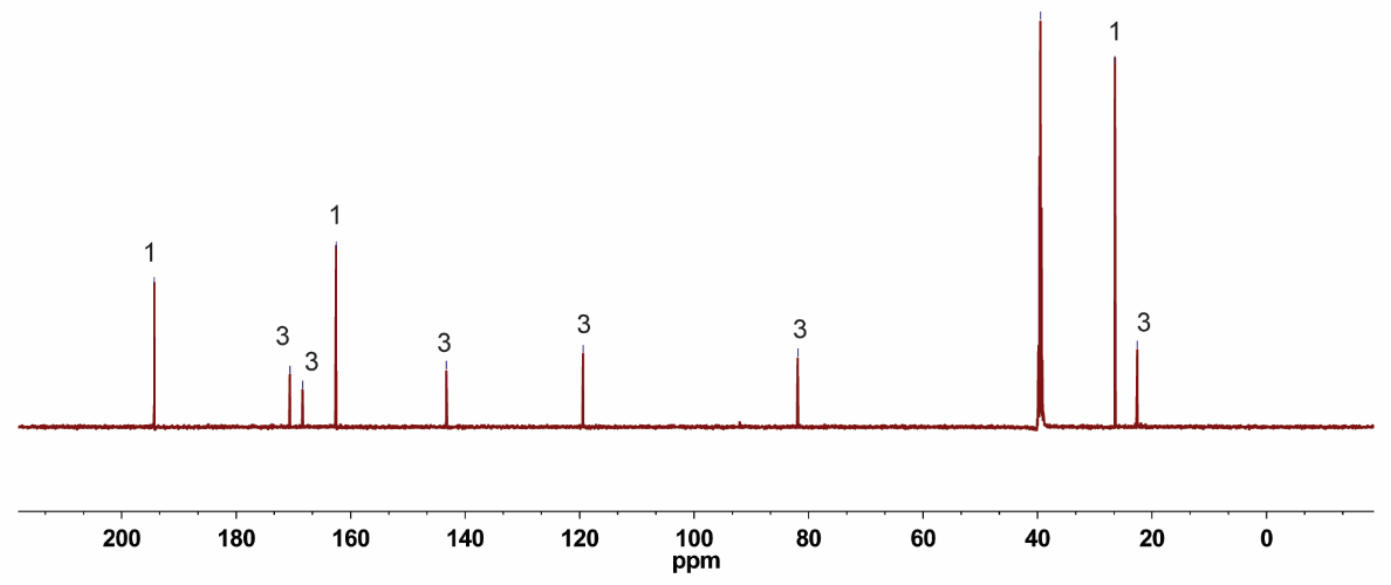

Figure S18. NMR Spectra of pyruvic acid neat liquid from a commercial source. 
A

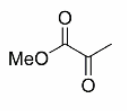

10
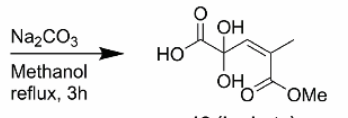

12 (hydrate)

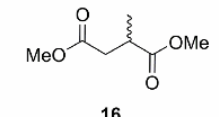

16

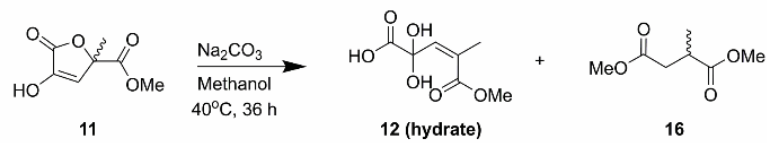

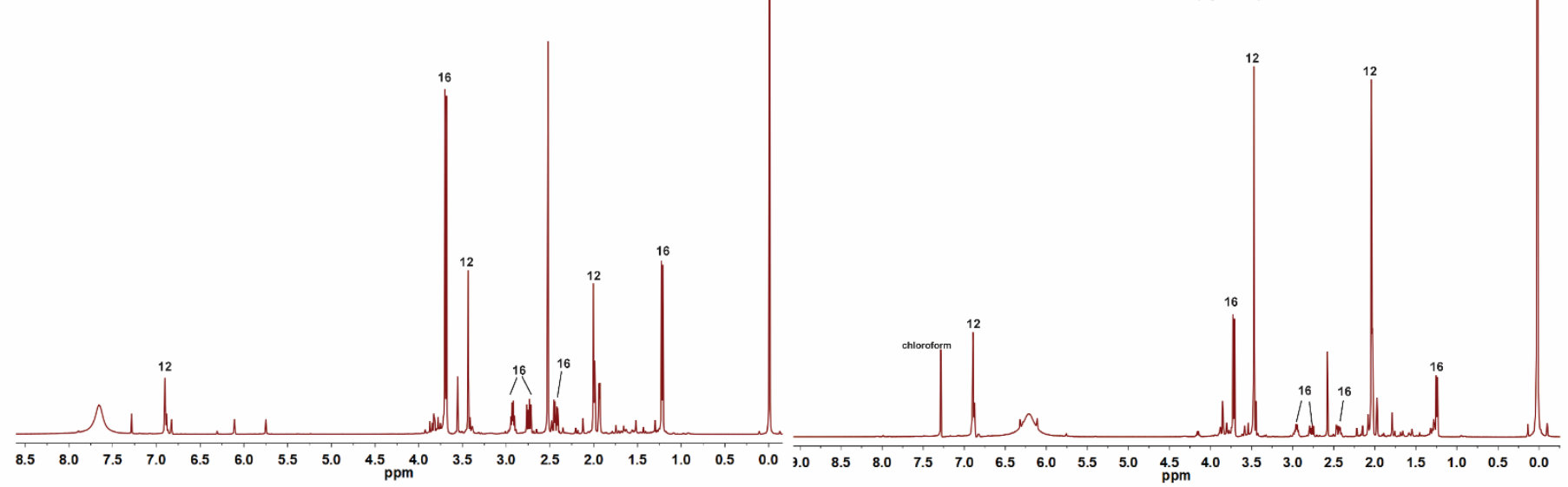

C

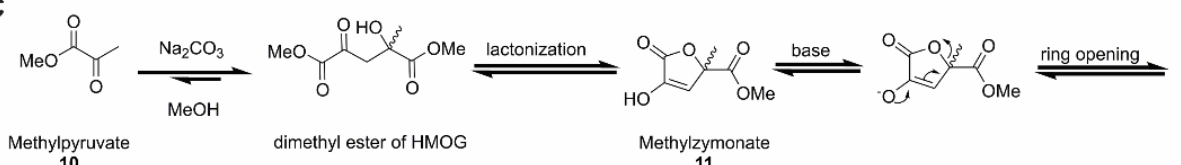

10

11
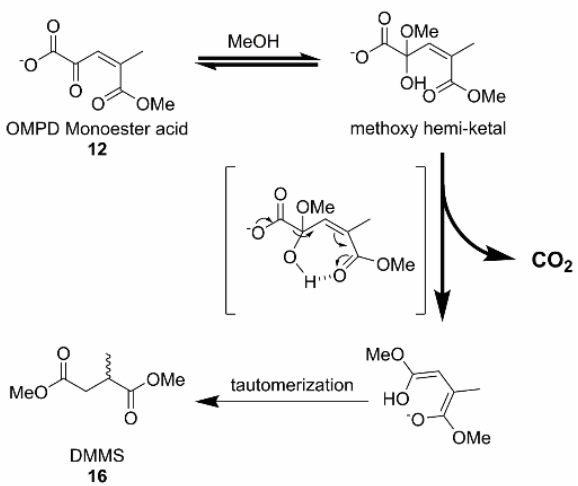

Figure S19. ${ }^{1} \mathrm{H}$ NMR spectra of crude reaction mixtures in the synthesis of 12. A. Analysis of the crude mixture after 3 hours of reflux $\left(65^{\circ} \mathrm{C}\right)$ revealed substantial formation of dimethyl-2methylsuccinate (16, DMMS), a product resulting from a proposed decarboxylation of 12 shown in panel C. B. Similar product diversity is formed when starting from compound 11, but 16 is less abundant due to the lower temperature employed and the use of a direct precursor to 12 . C. Proposed mechanism to account for formation of $\mathbf{1 6}$ in both pathways shown in panels $A$ and $B$ resulting from decarboxylation of $\mathbf{1 2 .}$ 


\section{References}

(1) Cooper, A. J. L.; Ginos, J. Z.; Meister, A. Synthesis and properties of the $\alpha$-keto acids. Chem. Rev. 1983, 83, 321-358.

(2) Helaine, V.; Rossi, J.; Gefflaut, T.; Alaux, S.; Bolte, J., Synthesis of 4,4-disubstituted L-glutamic acids by enzymatic transamination. Adv. Synth. Catal. 2001, 343, 692-697.

(3) Margolis, S. A.; Coxon, B. Identification and quantitation of the impurities in sodium pyruvate. Anal. Chem. 1986, 58, 2504-2510. 